First publ. in: Review of Physiology, Biochemistry and Pharmacology 150 (2003), pp. 1-35

\author{
H.-J. Apell
}

\title{
Structure-function relationship in P-type ATPases-a biophysical approach
}

\begin{abstract}
P-type ATPases are a large family of membrane proteins that perform active ion transport across biological membranes. In these proteins the energy-providing ATP hydrolysis is coupled to ion-transport that builds up or maintains the electrochemical potential gradients of one or two ion species across the membrane. P-type ATPases are found in virtually all eukaryotic cells and also in bacteria, and they are transporters of a broad variety of ions. So far, a crystal structure with atomic resolution is available only for one species, the SR Ca-ATPase. However, biochemical and biophysical studies provide an abundance of details on the function of this class of ion pumps. The aim of this review is to summarize the results of preferentially biophysical investigations of the three best-studied ion pumps, the Na,K-ATPase, the gastric H,K-ATPase, and the SR Ca-ATPase, and to compare functional properties to recent structural insights with the aim of contributing to the understanding of their structure-function relationship.
\end{abstract}

\section{Introduction}

All living cells are surrounded by membranes that separate their strictly controlled cytoplasmic contents from their environment, and within cells numerous compartments with specific functions and different compositions of components are enclosed also by membranes. These membranes consist of lipid bilayers, which are effective barriers for most of the water-soluble substances, such as ions, sugars, and amino acids. To perform its metabolism, a cell needs selective and controlled transport of substrates and of end products of the metabolic processes across these membranes. This transport function is performed by membrane proteins.

\footnotetext{
H.-J. Apell (-

Department of Biology,

University of Konstanz,

Fach M635, 78457 Konstanz, Germany

e-mail: h-j.apell@uni-konstanz.de
} 
Besides the separation of aqueous phases, a second function of membranes is the storage of energy in the form of chemical potential gradients, $\Delta \mu_{\mathrm{i}}=R T \cdot \ln \left(c_{\mathrm{i}}^{\prime} / c_{\mathrm{i}}^{\prime \prime}\right)$, of substances $i$ in the case of uncharged substances or in the case of ions in the form of electrochemical potential gradients, $\Delta \tilde{\mu}_{\mathrm{i}}=R T \cdot \ln \left(c_{\mathrm{i}}^{\prime} / c_{\mathrm{i}}^{\prime \prime}\right)+z_{i} F\left(\varphi^{\prime}-\varphi^{\prime \prime}\right)$.

On the basis of thermodynamic principles, two classes of transport proteins can be discriminated: proteins that perform passive and active transport. Passive transport is defined by facilitated diffusion "downhill" along the (electro-)chemical potential gradient of the transported substance whereby the energy gradient dissipates. Active transport occurs "uphill," increasing the (electro-) chemical potential of the transported substances. This is possible only if energy in the form of free energy, $\Delta G$, is provided from another process which is coupled to the transport across the membrane. This energy input has to be larger than the (electro-) chemical potential, $|\Delta G| g t ; \Delta \tilde{\mu}_{\mathrm{i}}$. Active ion-transport proteins in animals are mostly ion transporters, so-called ion pumps. A careful and detailed introduction into the biophysics of ion pumps can be found in the monograph Electrogenic Ion Pumps (Läuger 1991).

Energy sources that power active ion transport are light, e.g., in bacteriorhodopsin (Stoeckenius 1999; Der and Keszthelyi 2001; Lanyi and Luecke 2001), redox energy, e.g., in the cytochrome c oxidase (Michel 1999; Wikstrom 2000; Abramson et al. 2001), or decarboxylation, e.g., in ion-translocating decarboxylases (Dimroth 1987; Michel 1999; Wikstrom 2000; Abramson et al. 2001). The most common energy-producing mechanism is, however, ATP hydrolysis in transport ATPases.

Ion-motive ATPases are the largest and most diverse class of ion pumps. Three groups are discussed in the literature: (a) F-type ATPases (Dimroth et al. 2000; Papa et al. 2000; Capaldi and Aggeler 2002; Senior et al. 2002), which work in many cases in reverse direction as so-called ATP synthetases, e.g., in the inner mitochondrial membrane or in the thylakoid membrane of chloroplasts. (b) V-type ATPases (Sze et al. 1992; Nelson 1995; Forgac 1999) which are ubiquitous H-ATPases with a structure related to that of F-type ATPases. They are found in cellular organelles of an ever-increasing number of different cells. (c) P-type ATPases, which are found in virtually all eukaryotic cells and also in bacteria.

\section{P-Type ATPases}

In contrast to the other two types of ion-motive ATPases, P-type ATPases are of a much simpler structure (Møller et al. 1996). They have an $\alpha$-subunit of approximately $100 \mathrm{kDa}$ that contains all components essential for enzymatic activity and transport. Examples of such single-subunit P-type ATPases are, e.g., Ca-ATPases (Carafoli 1992; Lee and East 2001). Na,K-ATPase and H,K-ATPase are functional only if assembled together with a $\beta$ subunit (McDonough et al. 1990; Geering et al. 2000; Geering 2001). In the case of the $\mathrm{Na}, \mathrm{K}$-ATPase, in specific tissues a $\gamma$-subunit was found, which is also discussed as a regulatory device (Berrebi-Bertran et al. 2001; Cornelius et al. 2001; Therien et al. 2001). Meanwhile, a whole family of such regulators was identified, called FXYD proteins (Beguin et al. 2002; Garty et al. 2002). A K-ATPase of E. coli (the so-called Kdp-ATPase) is composed of three different polypeptides (Epstein et al. 1990; Altendorf et al. 1992).

A second fundamental difference between P-type ATPases and the other ion-motive ATPases is their enzymatic reaction mechanism (Glynn 1985; Lancaster 2002), which 


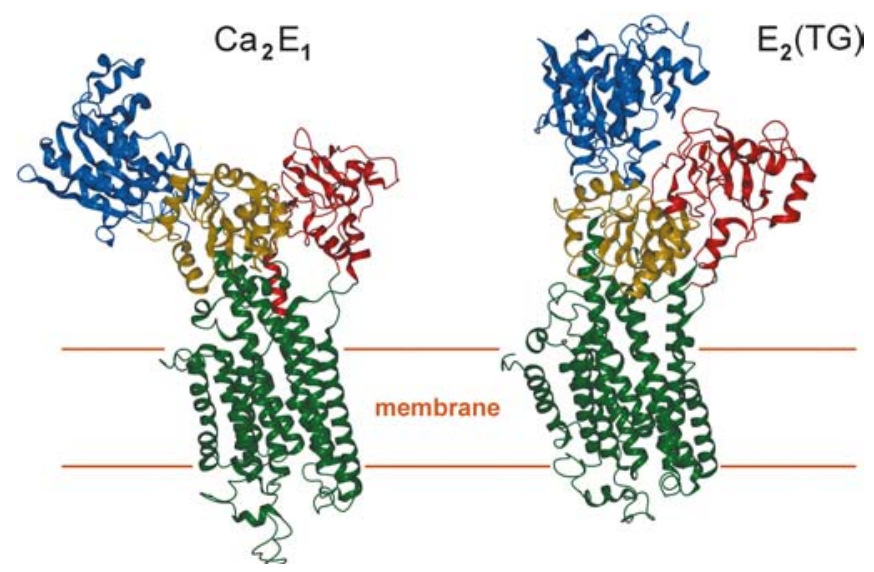

Fig. 1 Structure of the Ca-ATPase of the sarcoplasmatic reticulum in both principal conformations as resolved by their crystal structure. Left: In its conformation $\mathrm{Ca}_{2} \mathrm{E}_{1}$ (PDB file 1EUL) the spatial resolution was $2.6 \AA$ (Toyoshima et al. 2000). Right: The structure in the $\mathrm{E}_{2}$ conformation (PDB File 1IWO) was stabilized by tharpsigargin (not shown) and obtained from crystals with a resolution of $3.1 \AA$. (Toyoshima and Nomura 2002)

contains a phosphorylated intermediate. The $\gamma$ phosphate of ATP is transferred to a highly conserved aspartyl residue in the large cytoplasmic loop between the forth and fifth transmembrane segment. Specific to P-type ATPases is also that the enzymatic activity (and consequently ion transport) can be inhibited by ortho-vanadate, which acts as a tightly bound transition-state analogue of phosphate (Cantley et al. 1977).

P-type ATPases are found in virtually all eukaryotic cells and also in bacteria, where they actively transport various ions. They are distributed in different classes (I-IV) and several subgroups (Sweadner and Donnet 2001) according to the ions they transport: $\mathrm{Na}^{+}$, $\mathrm{K}^{+}, \mathrm{Ca}^{2+}, \mathrm{H}^{+}, \mathrm{Mg}^{2+}, \mathrm{Cu}^{2+}, \mathrm{Cd}^{+}, \mathrm{Hg}^{+}$, and even $\mathrm{Cl}^{-}$(Gerencser 1996).

\section{Structural properties}

Although their molar masses vary between about 70 and $100 \mathrm{kDa}$, the first five transmembrane domains and the large cytoplasmic loop, which forms the main part of the enzymatic machinery, are well conserved for all P-type ATPases. Yeast proteins mostly have six transmembrane domains, while those from animal tissues preferentially have ten (Sweadner and Donnet 2001).

A breakthrough in the understanding of structure-function relationships was made when the first highly-resolved 3D structure of a P-type ATPase became available with a resolution of $2.6 \AA$ (Fig. 1), the Ca-ATPase of the sarcoplasmatic reticulum in its $\mathrm{E}_{1}$ conformation with $2 \mathrm{Ca}^{2+}$ ions bound (" $\mathrm{Ca}_{2} \mathrm{E}_{1}$," Toyoshima et al. 2000). The structure confirms the topological organization of ten transmembrane helices deduced for $\mathrm{Ca}, \mathrm{Na}, \mathrm{K}-$, H,K- and H-pumps by biochemical techniques (MacLennan et al. 1985), and the structure reveals several unexpected features. It was found (Toyoshima et al. 2000) that (a) both ions are located side by side with a distance of $5.7 \AA$ close to the middle of the transmembrane section of the protein, (b) the ion binding sites are surrounded by the transmembrane 
helices M4-M6 and M8, (c) the $\alpha$ helices M4 and M6 are partly unwound to provide an efficient coordination geometry for the two $\mathrm{Ca}^{2+}$ ions, and (d) a cavity with a rather wide opening, surrounded by M2, M4, and M6 is discussed as an access structure on the cytoplasmic side. The outlet of $\mathrm{Ca}^{2+}$ is likely to be located in the area surrounded by M3-M5 . The details of $\mathrm{Ca}^{2+}$ occlusion sites fit well with that deduced in extensive mutagenesis studies (Clarke et al. 1989a, MacLennan et al. 1997). The parts of the protein protruding into the cytoplasm are divided into three domains, two domains, $\mathrm{N}$ (nucleotide) and $\mathrm{P}$ (phosphorylation), are formed by the loop between M4 and M5, well separated from a third A domain (actuator or anchor) formed by the loop between M2 and M3 and the tail leading into M1. The fold of the P-domain is like that of L-2-haloacid dehalogenase and related proteins with homologies to P-type pumps in conserved cytoplasmic sequences (Saraste et al. 1990; Aravind et al. 1998).

Recently, the structure of the SR Ca-ATPase in its second principle conformation, $\mathrm{E}_{2}$, stabilized by the specific inhibitor tharpsigargin ["E $\mathrm{E}_{2}(\mathrm{TG})$ "], became available with a resolution of $3.1 \AA$ (Toyoshima and Nomura 2002). Due to the low $\mathrm{Ca}^{2+}$-binding affinity in the $\mathrm{E}_{2}$ state, it was not possible to obtain crystals with $\mathrm{Ca}^{2+}$ ions bound which would allow a direct determination of the position of the binding sites. It was proposed that in $\mathrm{E}_{2}(\mathrm{TG})$ the counterions $\mathrm{H}^{+}$are bound and access to the luminal sites is already locked. Nevertheless, by comparison of both crystallized forms, $\mathrm{Ca}_{2} \mathrm{E}_{1}$ and $\mathrm{E}_{2}(\mathrm{TG})$, it is possible to describe a number of changes in the protein structure that are important for conclusions on functional properties related to enzymatic and transport activity. [These differences are impressively visualized as supplementary information to Toyoshima and Nomura (2002) on $\mathrm{Na}$ ture's website (www.nature.com).] The three cytoplasmic domains, N, P, and A, which form the enzymatic machinery, are wide open in the $\mathrm{Ca}_{2} \mathrm{E}_{1}$ form, and they are folded together to a much more compact assembly in the $\mathrm{E}_{2}$ (TG) form (Fig. 1). This transition requires movements of the $\mathrm{N}$ domain of about $50 \AA$ and a rotation of the A domain of about $110^{\circ}$. The cytoplasmic domains move as a whole in a M10-to-M1 direction (Toyoshima and Nomura 2002). The $\mathrm{P}$ and $\mathrm{N}$ domains themselves are not changed between both conformations.

Despite the previously often discussed concept that in the membrane domains no major structural rearrangements are expected between different conformations of the pump, the reported changes of position and tilt of the first six transmembrane helices are dramatic. The transition between $\mathrm{Ca}_{2} \mathrm{E}_{1}$ and $\mathrm{E}_{2}(\mathrm{TG})$ is rather complicated and includes partial unwinding of $\alpha$-helices, bending a part of an $\alpha$-helix by almost $90^{\circ}$ (M1), changing tilts (M2M5), $\sim 90^{\circ}$ rotations (M6), shifts towards the cytoplasmic side (M1, M2) or shifts in opposite direction by $5 \AA$, which is almost one turn of an $\alpha$-helix (M3, M4). (For more details see Toyoshima and Nomura 2002.) With respect to the cytoplasmic domains of the enzymatic machinery the interplay between these is obvious, and it is clearly possible to imagine the concept that $\mathrm{Ca}^{2+}$ binding has to trigger enzyme phosphorylation, and that a relaxation of the phosphorylated form (and release of the nucleotide) subsequently disrupts the ion binding sites as seen in the crystallized $\mathrm{E}_{2}(\mathrm{TG})$ conformation. The almost perfect coordination of both $\mathrm{Ca}^{2+}$ ions in $\mathrm{E}_{1}$ (Toyoshima et al. 2000) is abolished in $\mathrm{E}_{2}$ (TG) by a shift of M4 and a clockwise rotation of the three crucial residues on M6 out of site I (Toyoshima and Nomura 2002).

So far, the SR Ca-ATPase is the only P-type ATPase with such a detailed structural resolution. From other members of this family only images with a lower resolution of about $8 \AA$ are available (Kühlbrandt et al. 1998; Scarborough 1999; Hebert et al. 2000). A com- 
Fig. 2 Reaction scheme for a Ptype $\mathrm{H}$-ATPase. $\mathrm{E}_{1}$ and $\mathrm{E}_{2}$ are the conformations of the protein with ion-binding sites facing cytoplasm and extracellular medium, respectively. Certain transitions between neighboring states of the protein must be kinetically inhibited (dashed lines) to produce ATP-driven transport cycle (solid lines) that pumps $\mathrm{H}^{+}$ions out of the cell

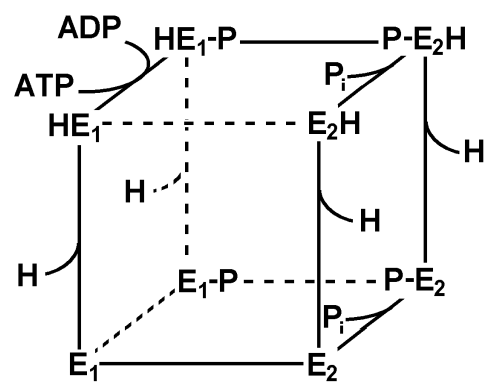

parison of such images with a similarly resolved SR Ca-ATPase structure (Zhang et al. 1998) indicates that they agree in most of the important structural details. Therefore, a computer approach was used in which the conserved homology, especially in the ATP hydrolysis site of the P-type ATPases (Jørgensen et al. 2001), as well as other aligned conserved segments, were mapped on the SR Ca-ATPase structure. Although the homology is highest for the Na,K-ATPase, this procedure led to reasonable results also for other P-type ATPases (Sweadner and Donnet 2001). Most insertions and deletions were predicted to be at the protein surfaces, and the similarity proposes a shared folding of all tested P-type ATPases, despite some particular exceptions.

Therefore, the structural features of the SR Ca-ATPase will be used in the following paragraphs to represent the considerations of structure-function principles of P-type ATPases.

\section{Principles of transport functions}

The eminent importance of the insights into structural details of the SR Ca-ATPase is paired with a functional analysis, which is most elaborate for the Na,K-ATPase. The transport mechanism found for this ion pump could be generalized for all P-type ATPases. Since enzymatic and transport functions have to be coupled, the pump mechanism has to be a complex process.

The analysis of the ion-transport process in P-type ATPases revealed that at least three categories of reactions have to occur, performed sequentially in forward or backward direction: (a) ion binding or release, (b) ion occlusion or deocclusion, and (c) transitions between both principal conformations in which the binding sites become accessible from the cytoplasm $\left(E_{1}\right)$ or from the opposite aqueous compartment $\left(E_{2}\right)$. Taking these reactions into account, a general reaction scheme can be constructed which has eight states in the simplest case of a H-ATPase that transfers one $\mathrm{H}^{+}$per hydrolyzed ATP (Fig. 2). If all transitions were allowed, such a protein would short-circuit the membrane for $\mathrm{H}^{+}$ions in the fashion of an ion carrier, and it would be able to dissipate the energy provided by ATP hydrolysis without ion transport. Therefore, a number of transitions have to be inhibited kinetically by the pump protein to perform active ion transport as indicated in Fig. 2 by dashed lines (Läuger 1991). Indeed, this reaction scheme was found to represent perfectly the function of a P-type H-ATPase from Enterococcus hirae (Apell and Solioz 1990). The transport of counterions, as found in most of the other P-type ATPases, can be constructed 
Fig. 3 Post-Albers cycle for the $\mathrm{Na}, \mathrm{K}-\mathrm{ATPase}$. $\mathrm{E}_{1}$ and $\mathrm{E}_{2}$ are conformations of the ion pump with ion binding sites facing the cytoplasm and extracellular medium, respectively. $\left(\mathrm{Na}_{3}\right) \mathrm{E}_{1}-\mathrm{P}, \mathrm{E}_{2}\left(\mathrm{~K}_{2}\right)$ and $\mathrm{E}_{2}\left(\mathrm{~K}_{2}\right) \cdot \mathrm{ATP}$ are occluded states in which the ions bound are unable to exchange with either aqueous phases. Enzyme phosphorylation and dephosphorylation occurs on the cytoplasmic side of the protein

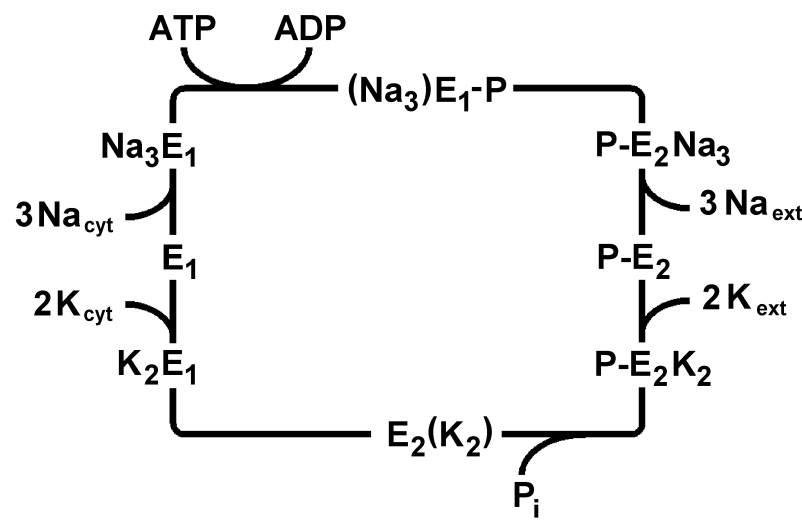

from such a simple scheme by stacking a second, analogous reaction cube underneath the one shown.

The Na,K-ATPase maintains the electrochemical potential gradient of $\mathrm{Na}^{+}$and $\mathrm{K}^{+}$ions across cell membranes (Läuger 1991; Apell 1997; Glitsch 2001; Jørgensen and Pedersen 2001). The ion transport is facilitated by coupling the energy-providing enzymatic process with a Ping-Pong mechanism of ion translocation. This process is described by the socalled Post-Albers cycle (Albers 1967; Post et al. 1972) which is in full agreement with the general scheme of Fig. 2. A representation of the Na,K-ATPase pump cycle is shown in Fig. 3. As can be seen from Fig. 3, the reaction sequence of ion binding, occlusion, conformation transition and ion release is performed for both transported ion species. In addition, coupling of the scalar enzymatic activity with the vectorial ion transport takes place in the occlusion reactions: enzyme phosphorylation by ATP together with $\mathrm{Na}^{+}$ion occlusion, and enzyme dephosphorylation together with $\mathrm{K}^{+}$ion occlusion. Under physiological conditions (i.e., at ATP concentrations above $50 \mu \mathrm{M}$ ), an additional reaction step was found: the so-called low-affinity ATP binding in state $\mathrm{E}_{2}\left(\mathrm{~K}_{2}\right)$. This reaction, $\mathrm{E}_{2}\left(\mathrm{~K}_{2}\right)+$ $\mathrm{ATP} \rightarrow \mathrm{E}_{2}\left(\mathrm{~K}_{2}\right)$.ATP, is not necessary to transport $\mathrm{K}^{+}$ions; however, it speeds up the subsequent conformation transition, $\mathrm{E}_{2}\left(\mathrm{~K}_{2}\right) \cdot \mathrm{ATP} \rightarrow \mathrm{K}_{2} \mathrm{E}_{1}$. ATP, by a factor of ten (Simons 1974; Glynn 1985).

Respective "Post-Albers"-type pump cycles were also found for the SR Ca-ATPase (de Meis 1985; Inesi and de Meis 1989), the Ca-ATPase of the plasma membrane (Schatzmann 1989), and the gastric H,K-ATPase (Faller et al. 1985; Helmich-de Jong et al. 1987; Sachs et al. 1992).

Significant differences were observed with respect to the stoichiometry of various Ptype ATPases. For Na,K-ATPase, gastric H,K-ATPase and SR Ca-ATPase counter-transport of ions was demonstrated. In the case of the Ca-ATPase, it was not so easy to verify counter-transport since the SR membrane is very leaky for monovalent cations so that neither electric membrane potentials nor $\mathrm{pH}$ gradients can be monitored reliably across the SR membrane. Only after reconstitution of the SR Ca-ATPase in proteoliposomes convincing evidence was produced that it is a Ca,H-ATPase (Yu et al. 1993, 1994). For a number of other ATPases, studies of the transport properties are not sufficiently advanced to establish counter-transport or stoichiometry.

The three best investigated P-type ATPases showed different stoichiometries: $3 \mathrm{Na}^{+} / 2$ $\mathrm{K}^{+} / 1$ ATP for the Na,K-ATPase, $2 \mathrm{H}^{+} / 2 \mathrm{~K}^{+} / 1$ ATP for the gastric $\mathrm{H}, \mathrm{K}$-ATPase, and 2 
Fig. 4 Profile of the potential energy of the proton along its pathway in states $\mathrm{HE}_{1},(\mathrm{H}) \mathrm{E}_{1}-\mathrm{P}$ and $\mathrm{P}-\mathrm{E}_{2} \mathrm{H}$. The high energy barriers symbolize a virtually impenetrable structure for an $\mathrm{H}^{+}$ion. $\alpha^{\prime}, \beta^{\prime}$, $\beta^{\prime \prime}$ and $\alpha^{\prime \prime}$ represent relative dielectric distances which characterize the fraction of the membrane potential that has to be traversed by ions between two neighboring pump states. In the occluded state, equilibration between binding site and aqueous phase is blocked on both sides. Nonzero values of the dielectric distances correspond to an electrogenic contribution. Dielectric and spatial distances are not necessarily the same

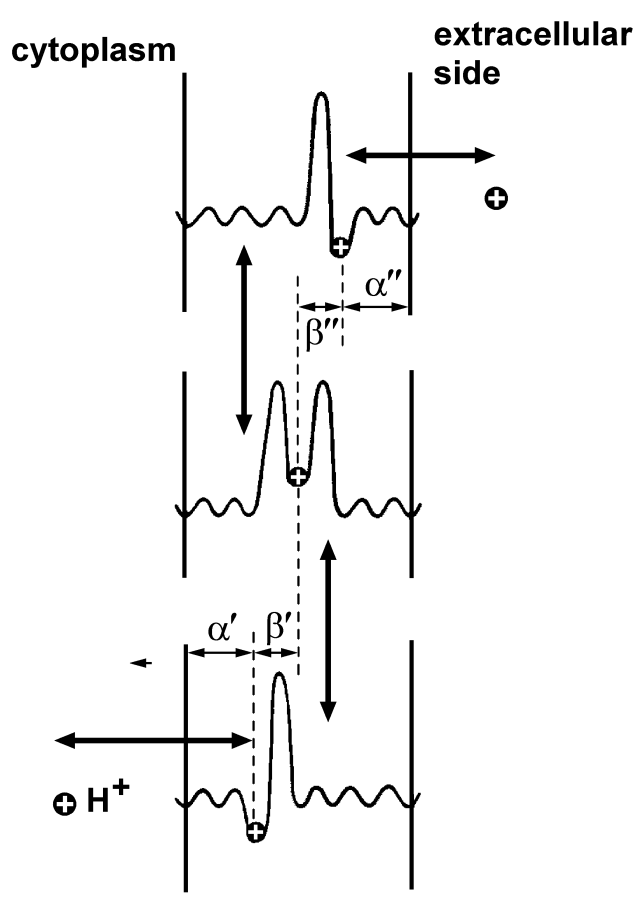

$\mathrm{Ca}^{2+} / 2 \mathrm{H}^{+} / 1$ ATP for the SR Ca-ATPase. From the amount of charges transported per cycle, an important parameter is determined-the electrogenicity of the pump. It is defined as the number of elementary charges moved out of the cytoplasm per molecule ATP hydrolyzed. From the numbers given above, the following electrogenicities are obtained: +2 (SR Ca-ATPase), +1 (Na,K-ATPase) and 0 (gastric H,K-ATPase). However, even when no net charge is translocated across the membrane, as in the case of the H,K-ATPase, ions are moved through the membrane (or protein) dielectric. Therefore, while proceeding through each half cycle of the respective Post-Albers scheme, charge movements have to occur. An important question is: which of the four steps of a half cycle, (a) ion binding, (b) ion occlusion, (c) conformation transition, and (d) ion release to the opposite side, is associated with a shift of charge(s) within the membrane dielectric, and how large is its contribution to the total charge movement?

To quantify such charge movements we consider a potential-energy profile of an ion along its transport pathway in different states of a half cycle (Fig. 4). For the sake of simplicity, again an H-ATPase is chosen which transports one $\mathrm{H}^{+}$. The "dielectric" distance (or "dielectric coefficient") was introduced as a characteristic parameter to describe the fraction of membrane dielectric over which the charge is shifted perpendicular to the plane of the membrane (Läuger 1991). If a dielectric coefficient is nonzero, the respective reaction step in the Post-Albers scheme is termed "electrogenic." In Fig. 4, for example, the dielectric coefficient for cytoplasmic binding of a $\mathrm{H}^{+}$ion would be $\alpha^{\prime}$. According to the conservation principle, the conservation condition, $\alpha^{\prime}+\beta^{\prime}+\beta^{\prime \prime}+\alpha^{\prime \prime}=1$, has to be fulfilled for the transfer of each ion across the whole membrane.

When the ion-binding sites are inside the membrane part of the protein, as was shown for the SR Ca-ATPase (Toyoshima et al. 2000), for the access to these sites two different 
limiting cases can be considered: The access may take the form of a wide, water-filled funnel (or vestibule) or a narrow channel which even may require (partial) dehydration of the ions or which may be selective for the transported ion species. The difference between both cases is that in the case of a vestibule, water and all kinds of ions can enter so that the electrical conductance is large, no electrical field can build up, and the drop of the transmembrane electric potential is negligible. In the other case, part of the transmembrane electric potential will drop across the length of the channel and, therefore, generate a socalled high-field access channel or "ion well" (Mitchell and Moyle 1974; Läuger and Apell 1986). Only in the latter case the movement of ions is electrogenic.

\section{Detection of transport functions}

Various experimental techniques were developed and applied to study and analyze transport functions of P-type ATPases. The most comprehensive investigations were performed with the $\mathrm{Na}, \mathrm{K}-\mathrm{ATPase}$. Therefore, in the following paragraphs the various presented experimental techniques will mainly refer to publications on transport properties of this ion pump.

\section{Tracer flux studies}

The counter-transport of $\mathrm{Na}^{+}$and $\mathrm{K}^{+}$allows detailed studies of ion movements in both directions through the membrane. Since no $\mathrm{K}^{+}$isotopes with convenient half-life times, $t_{1 / 2}$, are available, ${ }^{86} \mathrm{Rb}$ was used instead. It has a $t_{1 / 2}$ of 18.7 days, and $\mathrm{Rb}^{+}$is a congener of $\mathrm{K}^{+}$ with similarly high binding affinity (Karlish et al. 1978; Beaugé and Glynn 1979; Glynn and Richards 1982; Schneeberger and Apell 2001). Transport studies were performed in compartmentalized preparations, such as erythrocytes (Sen and Post 1964; Karlish and Glynn 1974; Sachs 1977; Beauge and Glynn 1978), inside-out vesicles of red blood cells (Blostein 1979, 1983), and reconstituted proteoliposomes (Anner et al. 1977; Anner and Moosmayer 1981; Karlish and Pick 1981; Karlish et al. 1982; Cornelius 1991). A rapid filtration method for time-resolved measurements of isotope flux from membrane vesicles was introduced by Forbush with a time resolution of about $30 \mathrm{~ms}$ (Forbush, III 1984a, 1984b, 1987). Isotope-flux experiments allow the determination of stoichiometries, ion occlusion, and transmembrane movements. However, due to the limited time resolution, kinetical analyses are possible only for slow processes. In the case of the SR Ca-ATPase, radioactive $\mathrm{Ca}$ isotopes were used to demonstrate sequential binding of the two $\mathrm{Ca}^{2+}$ ions and transport in the so-called single-file mode (Inesi 1987).

\section{Electrophysiological approaches}

A second and by far wider approach to study transport functions and kinetics are electrophysiological methods. In this field especially the Na,K-ATPase was scrutinized. The CaATPase in SR membranes cannot be measured by direct electric techniques since the (leak) conductance of this membrane is high due to the permeability for monovalent ions. The field of methodological approaches for the Na,K-ATPase reaches from investigation of whole epithelia (Horisberger and Giebisch 1989) to squid axon (Rakowski et al. 1987), 
cardiac myocytes (Gadsby et al. 1985; Nakao and Gadsby 1986), Purkinje cells (Glitsch and Tappe 1995) and giant membrane patches (Hilgemann 1994). Neurospora cells were used to study a H-ATPase (Slayman and Sanders 1985). Injection of mRNA into oocytes became a very successful technique, not only to investigate in a convenient way different isoforms of the $\mathrm{Na}, \mathrm{K}$-ATPase, but also to study mutated pumps or chimera between $\mathrm{Na}, \mathrm{K}$ ATPase and H,K-ATPase or SR Ca-ATPase (Lafaire and Schwarz 1985; Horisberger et al. 1991; Jaunin et al. 1993; Zhao et al. 1997; Mense et al. 2000). Additional access to the $\mathrm{Na}, \mathrm{K}$-ATPase expressed in oocytes was obtained by the cut-open technique that allows internal perfusion of the oocytes in a simple way (Holmgren and Rakowski 1994). In such cellular membrane systems both sides of the membrane are accessible separately and besides transmembrane pump currents, the current-voltage dependencies of the ion pumps can be determined. These so-called I-V curves provide important information on the pump mechanism (Läuger and Apell 1988; Läuger 1991; de Weer et al. 2000). In experiments with native membranes, a prominent problem is the presence of various other ion-transport systems, such as ion channels and ion carriers, which may produce electric currents larger than that from ion pumps. Therefore, the other ion-transport proteins have to be blocked by inhibiting agents, and the residual currents have to be measured in the absence and presence of specific pump inhibitors. The difference of the currents in the absence and presence of the inhibitor represents the pump-specific ion transport. Certain cardiac glycosides are appropriate inhibitors for those experiments in the case of the Na,K-ATPase (Lederer and Nelson 1984; Gadsby 1984).

To overcome the difficulties of native membranes, a supplementary approach was chosen in which purified membrane preparations were used so that the only remaining transport protein was the Na,K-ATPase (Jørgensen 1974). Since the resulting membranes are no longer vesicular but flat membrane patches which have sizes in the order of $1 \mu \mathrm{m}$ diameter or less (although they have densities of up to 7,000 pump molecules per $\mu \mathrm{m}^{2}$ ), their transport properties cannot be measured directly with electrodes on both sides of the membrane. However, they became accessible to electric studies on the basis of a proposal by Peter Läuger who suggested adsorbing the Na,K-ATPase-containing membranes onto black lipid membranes (BLM) and triggering the pump action with an ATP-concentration jump by release of ATP from its inactive precursor, caged ATP (Fendler et al. 1985; Borlinghaus et al. 1987; Apell et al. 1987; Fendler et al. 1988, 1993; Sokolov et al. 1998). This method was also applied in studies of the SR Ca-ATPase (Hartung et al. 1987) and of the gastric H,K-ATPase (Fendler et al. 1988). A more recent development in this technique is the use of so-called solid-supported membranes, which are much more stable than BLM and which allow an easy exchange of the buffer composition (Seifert et al. 1993; Pintschovius and Fendler 1999; Domaszewicz and Apell 1999).

Reconstitution of Na,K-ATPase in BLMs turned out to be tricky since the ions pumps tend to denature and to form ion-channel-like structures during this procedure (Reinhardt et al. 1984). The results with incorporated, active ion pumps were not easily reproducible and generated rather small currents under turnover conditions (Eisenrauch et al. 1991). Similar small currents (<30 fA) were reported for reconstituted SR Ca-ATPase (Eisenrauch and Bamberg 1990; Nishie et al. 1990).

Measurements of the electric current through the $\mathrm{Na}, \mathrm{K}$-ATPase can be combined with tracer flux experiments to analyze transport stoichiometry in squid axon (de Weer et al. 1988, 2001) and in oocytes (Schwarz and Gu 1988; Rakowski 1989). 
Fig. $5 \mathrm{pH}$ and conformation dependence of the 5-IAF label covalently linked to rabbit $\alpha 1$ Na,K-ATPase. The conformation-dependent shift of the titration curve fitted through the experimental data indicates that the local $\mathrm{pH}$ in the environment of the label is modified by rearrangements of amino-acid side chains. The respective $\mathrm{pK}$ values of the curves are $6.55\left(\mathrm{Na}_{3} \mathrm{E}_{1}\right)$, $6.7\left(\mathrm{E}_{1}\right)$ and $6.8\left(\mathrm{E}_{2}\left(\mathrm{~K}_{2}\right)\right)$. The conformation-induced shift explains the fluorescence changes when the detection is performed at constant bulk pH

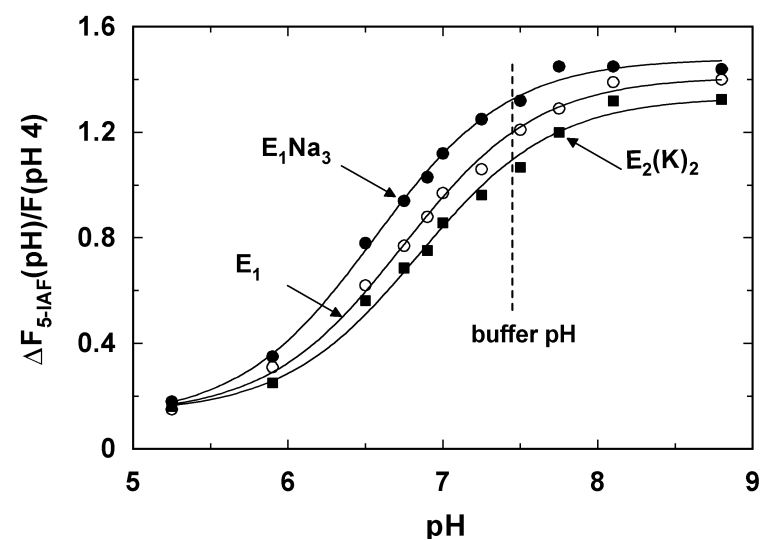

Fluorescence methods

Over the past two decades fluorescence methods were advanced to gain detailed information on structural changes and transport properties of P-type ATPases. Intrinsic tryptophan fluorescence (Karlish and Yates 1978; Boldyrev et al. 1983; Demchenko et al. 1993; Møller et al. 1996; Ferreira and Coelho-Sampaio 1996) as well as the fluorescence of covalently bound labels or of membrane soluble dyes ("extrinsic fluorescence") can be used to detect function-dependent responses of the proteins.

The first set of applied labels were fluoresceine derivatives which could be bound covalently to specific amino acids and which reported conformational changes. Fluorescein-5isothiocyanate (FITC) binds to Lys-501 within the ATP-binding site and thus prevents ATP binding and enzyme phosphorylation by ATP (Hegyvary and Post 1971; Sen et al. 1981; Farley and Faller 1985). However, FITC responds with a significant fluorescence change to the conformation transition between $\mathrm{E}_{1}$ and $\mathrm{E}_{2}$ (Rephaeli et al. 1986; Karlish 1988). Recently it was demonstrated that FITC also reports binding of the third $\mathrm{Na}^{+}$ion to the Na,K-ATPase (Schneeberger and Apell 1999). Due to the high conservation of the ATP-binding site in the P-type ATPases, FITC binding could be performed successfully also with SR Ca-ATPase (Kirley et al. 1985; Seidler et al. 1989) and with gastric H,KATPase (Asano et al. 1989; Faller et al. 1991).

The second fluoresceine derivative that detects conformation transitions of the Na,KATPase is 5-iodoacetamidofluorescein (5-IAF) (Kapakos and Steinberg 1982, 1986). This label binds to Cys-457 (Tyson et al. 1989), well away from the ATP binding site, so that the protein can be phosphorylated by ATP and is able to perform its complete pump cycle, a clear advantage over the FITC label. However, for the $\alpha 1$ isoforms of the Na,K-ATPase from various animals, the substrate-induced fluorescence changes of 5-IAF showed significant differences: no responses were found in pig enzyme, intermediate responses in rabbit enzyme, and maximal responses in dog enzyme (Steinberg and Karlish 1989; Stürmer et al. 1989). The underlying mechanism of these fluoresceine labels is that of a $\mathrm{pH}$ indicator which responds to small $\mathrm{pH}$ changes in the local environment of the label. In Fig. 5, pH titrations of the 5-IAF fluorescence intensity are shown for three different states of labeled rabbit kidney $\mathrm{Na}, \mathrm{K}-\mathrm{ATPa}$. It can be seen that changes of the protein conformation, induced by additions of substrates such as $\mathrm{Na}^{+}$, ATP, and $\mathrm{K}^{+}$, shift the titration curves, probably due to small variations of the protein-surface shape near the attached fluorescent label 
and, in consequence, charged amino-acid side chains affect the local ion concentration on the protein surface (by a Guy-Chapman effect) and, consequently, also the local $\mathrm{pH}$. When the bulk $\mathrm{pH}$ is buffered, as it was in the experiments performed to study the pump action, the fluorescence intensity is modulated with protein-conformation changes.

Further fluorescent labels applied to monitor conformational changes are eosin (Skou and Esmann 1981, 1983; Lin et al. 1997) and erythrosin 5'-isothiocyanate (Linnertz et al. 1998a, 1998b). Various fluorescent labels which can be bound simultaneously at different locations of the pump protein can also be used to determine distances between selected domains by the Förster resonance energy transfer mechanism (Linnertz et al. 1998b).

Fluorescent probes were also used to detect ion transport by P-type ATPases. In such studies, ion pumps are reconstituted in lipid vesicles, in which the inside-out oriented ATPases can be activated by addition of ATP, and transport activity is monitored by a fluorescence response to the generated electric membrane potential due to the electrogenicity of the ion pump. For a quantitative analysis, inhomogeneities of the vesicles in diameter and number of active pump molecules have to be taken into account (Apell and Läuger 1986). Appropriate dyes are 1,3,3,1',3',3'-hexamethylindodicarbocyanine (NK529; Apell et al. 1985), oxonol VI (Apell and Bersch 1987) and the carbocyanine dye DiS-C3-(5) (Goldshlegger et al. 1987). These dyes redistribute between aqueous phase and membrane as a function of the membrane potential across the membrane. Therefore, their time resolution is limited by the redistribution process. Typical time constants are on the order of $300 \mathrm{~ms}$ (Clarke and Apell 1989). With these assays, numerous transport properties could be determined for the Na,K-ATPase (Cornelius 1989; Clarke et al. 1989b, Goldshleger et al. 1990; Apell et al. 1990), for the SR Ca-ATPase (Cornelius and Møller 1991; Yu et al. 1993, 1994), and for a H-ATPase from Enterococcus hirae (Apell and Solioz 1990). The H,K-ATPase cannot be studied with such an approach due to its overall electroneutrality.

Styryl dyes, such as RH160, RH237, and RH421, were used since 1988 to trace pump activity of the Na,K-ATPase (Klodos and Forbush, III 1988; Bühler et al. 1991). These dyes, and others of this family, are hydrophobic compounds of amphiphilic character, which insert into lipid membranes in an aligned manner (Pedersen et al. 2001). Due to their electrochromic mechanism, they detect changes of local electric fields in the membrane dielectric (Loew et al. 1979; Fluhler et al. 1985) and, therefore, report charge movements in membrane preparations in which ion pumps are present in a sufficiently high density $\left(>10^{3} / \mu \mathrm{m}^{2}\right.$; Pedersen et al. 2001). Styryl dyes are so-called fast dyes since their response times are in a submicrosecond range. They can be applied to membrane vesicles or to open membranes, such as purified microsomal preparations of the Na,K-ATPase, so that a transmembrane ion transport is not detected but movements of ions into the membrane domains of the ion pumps or their release into the aqueous phase are detected (Stürmer et al. 1991). (RH421 can also be used to follow the transmembrane potential generated by $\mathrm{Na}, \mathrm{K}-\mathrm{ATPase}$ action; however, typical fluorescence changes were $15 \%$ per $100 \mathrm{mV}$ transmembrane potential, while oxonol VI showed about $100 \%$ change in the same experiment.) With respect to the Na,K-ATPase, a variety of styryl dyes were tested which produced differently large responses for the electrogenic partial reactions (Bühler et al. 1991; Fedosova et al. 1995; Pedersen et al. 2001). With this method, a wide spectrum of partial reactions of the $\mathrm{Na}, \mathrm{K}-\mathrm{ATPase}$ was studied and analyzed which resulted in an advanced understanding of ion binding affinities (Stürmer et al. 1991; Bühler and Apell 1995; Schneeberger and Apell 1999, 2001), rate constants of single reaction steps (Pratap and 
Robinson 1993; Heyse et al. 1994; Visser et al. 1995; Clarke et al. 1998; Humphrey et al. 2002) and the energetics of the pump cycle (Apell 1997).

Styryl dyes were also used to investigate an H-ATPase from Neurospora (Nagel et al. 1991), the SR Ca-ATPase (Butscher et al. 1999; Peinelt and Apell 2002), and recently the possibility of a comparable application with the gastric H,K-ATPase was demonstrated (Diller et al. 2003).

\section{Inhibitors}

All P-type ATPases may be functionally blocked by inhibitors. A common inhibitor of all P-type ATPases is ortho-vanadate, which binds with significantly higher affinity than phosphate to the phosphorylation site (Cantley et al. 1977; Stankiewicz et al. 1995) and blocks the pumps in their occluded $\mathrm{E}_{2}$ state. Specific inhibitors for the different ATPases are widely used to discriminate the activity of a single pump species or to "freeze" the protein in a defined conformation.

The Na,K-ATPase has been known for half a century to be inhibited by cardiac glycosides (Schatzmann 1953), a whole family of compounds of which ouabain is the most well known (Glynn 1985). Cardiac glycosides block the Na,K-ATPase from the outside of the membrane.

In the case of the gastric H,K-ATPase, a well-known inhibitor is the compound $\mathrm{SCH} 28080$, which also inactivates from the outside of the cell by blocking the access of the binding sides for $\mathrm{K}^{+}$ions (Keeling et al. 1988; Vagin et al. 2002).

The most frequently used inhibitor of the SR Ca-ATPase is tharpsigargin (Lytton et al. 1991; Inesi and Sagara 1992). It blocks the protein in its $\mathrm{E}_{2}$ conformation and the interaction between inhibitor and protein is known in detail since it could be resolved in the crystal structure of the protein-inhibitor complex (Toyoshima and Nomura 2002).

\section{Detailed ion-transport mechanism}

The methods introduced above were used during the last two decades to resolve the pump mechanisms of a number of P-type ATPases. The three ion pumps for which detailed information is available will be discussed in the following paragraphs. Since the number of publications that contain contributions to the mechanism is so large, in the following paragraphs, references will be provided mainly to recent review-type articles, which allow access to the abundance of data, and to a few articles which contain important new insights.

\section{Na,K-ATPase}

The Na,K-ATPase is a crucial transport protein of all animal cells which maintains the electro-chemical potentials for $\mathrm{Na}^{+}$and $\mathrm{K}^{+}$ions across the cytoplasmic membrane at the expense of ATP hydrolysis. The $\mathrm{K}^{+}$concentration gradient controls mainly the electric membrane potential, which is reflected by the fact that the electrochemical gradient for $\mathrm{K}^{+}$ is close to its thermodynamical equilibrium. In contrast, the electrochemical potential for $\mathrm{Na}^{+}$is kept far away from its equilibrium and is, therefore, an energy source for many transmembrane processes, such as the initial part of the action potentials in excitable cells 
and secondary active transport proteins which couple uphill transport of sugars, amino acids, or $\mathrm{Ca}^{2+}$ ions to the downhill movement of $\mathrm{Na}^{+}$. (For a review see Läuger 1991.)

Recent synopses on the investigation of ion transport by the Na,K-ATPase can be found in several reviews (de Weer et al. 2000; Pavlov and Sokolov 2000; Apell and Karlish 2001). As can be seen from the Post-Albers scheme in Fig. 3, the ion transport can be split into a sequence of outward $\mathrm{Na}^{+}$transport followed sequentially by an inward $\mathrm{K}^{+}$transport. Both branches were analyzed in great detail.

Forward $\mathrm{Na}^{+}$transport, $\mathrm{E}_{1}+3 \mathrm{Na}^{+}{ }_{\text {cyt }} \rightarrow \mathrm{E}_{2}-\mathrm{P}+3 \mathrm{Na}^{+}{ }_{\text {ext }}$, requires ATP, and ATP hydrolysis occurs only with $3 \mathrm{Na}^{+}$bound to the protein. Even if only $\mathrm{Na}^{+}$ions are present on the cytoplasmic side of the pump, virtually no transition into a state $\mathrm{E}_{2}\left(\mathrm{Na}_{2}\right)$ has been found, in contrast to other congener cations $\left(\mathrm{K}^{+}, \mathrm{Rb}^{+}, \mathrm{Cs}^{+}, \mathrm{NH}_{4}{ }^{+}, \mathrm{Tl}^{+}\right)$, which antagonize $\mathrm{Na}^{+}$binding and cause a conformational change into the occluded $\mathrm{E}_{2}$ state after two ions have bound. The virtual absence of the state $\mathrm{E}_{2}\left(\mathrm{Na}_{2}\right)$ is in agreement with the observation that binding of the third $\mathrm{Na}^{+}$ion occurs with a higher affinity than binding of the second, and stabilizes the protein in the $\mathrm{Na}_{3} \mathrm{E}_{1}$ state. This can be understood only by assuming that the third $\mathrm{Na}$ binding site becomes available after two $\mathrm{Na}^{+}$ions have already bound (Schneeberger and Apell 2001). Binding of the first two $\mathrm{Na}^{+}$ions was found to be apparently electroneutral (like binding of $2 \mathrm{~K}^{+}$ions or their congeners); binding of the third $\mathrm{Na}^{+}$ ion is electrogenic with a dielectric coefficient of 0.25 (Domaszewicz and Apell 1999). The time resolution of the techniques available to study cytoplasmic $\mathrm{Na}^{+}$binding is not yet high enough to determine the rate constant of these reaction steps; only equilibrium dissociation constants could be obtained. Occupation of the third, highly selective $\mathrm{Na}^{+}$ binding site, which is also formed by transmembrane parts of the Na,K-ATPase, is strictly correlated with a detectable effect on the fluorescent FITC-labeled enzyme. This is interpreted as an $\mathrm{Na}^{+}$-induced structural transition in the nucleotide binding site, probably a transition state between the "open" configuration of the N, P, and A domains of the cytoplasmic part of the protein to a more compact or "closed" one as observed in the $\mathrm{E}_{2}$ conformation, as can be seen in Fig. 1 (Toyoshima and Nomura 2002). This transition includes a movement of bound ATP into a position where its $\gamma$ phosphate becomes able to coordinate with Asp-371, the phosphorylation site. Thus, binding of the third $\mathrm{Na}^{+}$ion enables the enzyme to become phosphorylated, and this "trigger" ensures that no ATP is wasted unless three $\mathrm{Na}^{+}$ions are bound inside the pump. The subsequent phosphorylation of the enzyme is correlated with an occlusion of the three $\mathrm{Na}^{+}$ions, $\mathrm{Na}_{3} \mathrm{E}_{1}$.ATP $\rightarrow$ $\left(\mathrm{Na}_{3}\right) \mathrm{E}_{1}-\mathrm{P}+\mathrm{ADP}$. This process is electroneutral, i.e., no net charge movement within the membrane domain could be detected (Borlinghaus et al. 1987). Therefore, the rate constants of this step could be determined only indirectly. Assuming that the enzymatic and transport-coupled reaction are tightly correlated, the rate constants of enzyme phosphorylation, obtained by experiments with radioactive ATP, can be accepted as reference value. The phosphorylation-induced occluded state, $\left(\mathrm{Na}_{3}\right) \mathrm{E}_{1}-\mathrm{P}$, is only transient; it cannot be stabilized (unless the protein is treated by oligomycin).

When phosphorylated by ATP, the enzyme performs a conformational transition into its $\mathrm{E}_{2}-\mathrm{P}$ states, in which the bound $\mathrm{Na}^{+}$ions are successively deoccluded and released. The voltage sensitivity of this partial reaction was demonstrated with internally perfused squid giant axons and the major component of charge movement was assigned to the $\mathrm{Na}^{+}$release (or binding) steps (Gadsby et al. 1993). While the conformational relaxation is of minor electrogenicity, the release of the first $\mathrm{Na}^{+}$to the extracellular aqueous phase is the dominant charge-carrying step. It was found that this ion moves through $65 \%-70 \%$ of the pro- 


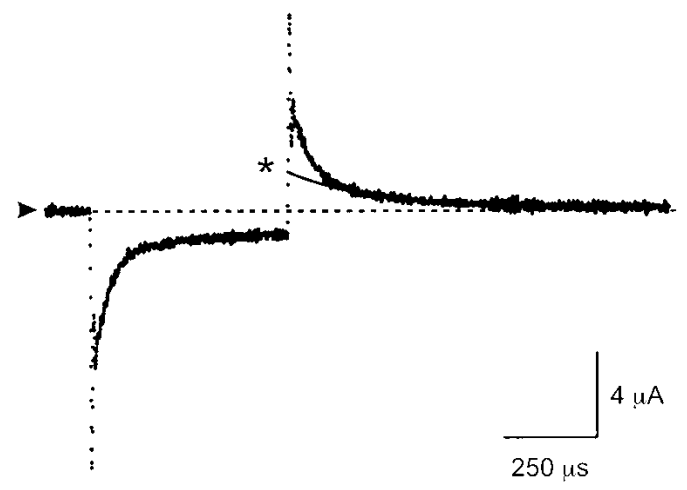

Fig. 6 Electric current caused by extracellular release of $\mathrm{Na}^{+}$from the $\mathrm{Na}, \mathrm{K}-\mathrm{ATPa} e$ in the membrane of a giant squid axon. The charge movement was elicited by a $500 \mu \mathrm{s}$-step from 0 to $-110 \mathrm{mV}$ (Holmgren et al. 2000). From such data the presence of three time constants in the range of $<30 \mu \mathrm{s}, 250 \mu$ s and $>4 \mathrm{~ms}$ can be derived by fitting with three exponential functions. These processes reflect the $\mathrm{Na}^{+}$movements through their "access channel" and intermediate relaxations of the protein structure that deoccluded the binding sites. (From Holmgren at al. 2000, with kind permission)

tein dielectric (Wuddel and Apell 1995). This may be explained by a narrow and deep access channel or "ion well" between the binding site in the protein and the aqueous outside of the protein. The release of the first $\mathrm{Na}^{+}$is followed by another conformational relaxation, which brings the remaining two $\mathrm{Na}^{+}$ions "electrically" closer to the extracellular aqueous phase because their release in the next reaction steps contributes with dielectric coefficients of 0.1-0.2 only. As shown in Fig. 6, the kinetics of deocclusion/release reactions has been analyzed recently and was found to occur with increasing rate constants from the first ion $\left(\leqq 1000 \mathrm{~s}^{-1}\right)$ to the third ( $\geqq 10^{6} \mathrm{~s}^{-1}$; Holmgren et al. 2000). The reduced electrogenicity of the second and third $\mathrm{Na}^{+}$-release step is matched by corresponding dielectric coefficients of $\mathrm{K}^{+}$binding (Rakowski et al. 1990), which are the reaction steps following under physiological conditions. Thus, the ion release process may be explained by assuming that the first $\mathrm{Na}^{+}$ion moves through a narrow and long access channel while the next two $\mathrm{Na}^{+}$ions released face a shallow channel. At least two different mechanisms could explain the transformation from a "deep" to "shallow" ion-well after release of the first $\mathrm{Na}^{+}$ion: (a) In a major structural rearrangement of the protein, the narrow ion well widens to become a large vestibule, which then is filled by electrolyte so that the electricpotential surface will come close to the binding sites, or (b) small rearrangements of the $\alpha$ helices allow water molecules to penetrate into the protein matrix from the outside and thus increase the dielectric constant in between binding sites and aqueous phase significantly. This process would also deform the shape of the electric potential within the protein. The latter mechanism would also enable an immediate rehydration of the ions when they are released from their sites without having to migrate as unscreened charges through protein matter whose polarization would be rather energy consuming.

There is convincing experimental evidence that $\mathrm{K}^{+}$transport is electroneutral, i.e., that no net charge is moved within the protein between states $\mathrm{E}_{2}-\mathrm{P}\left(\mathrm{K}_{2}\right)$ and $\mathrm{E}_{1}$ (Goldshlegger et al. 1987; Rakowski et al. 1990; Domaszewicz and Apell 1999). However, under physiological conditions, the extracellular $\mathrm{K}^{+}$concentration is far above the half-saturating concentration of the ion sites so that an electrogenic $\mathrm{K}^{+}$binding would be hidden in experi- 
ments under this condition (Läuger and Apell 1988). Detailed studies of extracellular $\mathrm{K}^{+}$ binding steps proved indeed its electrogenicity (Rakowski et al. 1990; Bielen et al. 1991; Bühler and Apell 1995; Peluffo and Berlin 1997).

The partial reaction between $\mathrm{E}_{2}-\mathrm{P}\left(\mathrm{K}_{2}\right)$ and $\mathrm{E}_{1}$ can be investigated in the so-called $\mathrm{K}^{+} /$ $\mathrm{K}^{+}$exchange mode, in the presence of $\mathrm{K}^{+}$, with or without $\mathrm{Mg}^{2+}$ and with inorganic phosphate, $\mathrm{P}_{\mathrm{i}}$. The experimental findings were explained under the assumptions that (a) the positive charges of the two ions are counter-balanced by two negative charges of the protein, (b) the binding sites in state $\mathrm{E}_{2}-\mathrm{P}$ are located inside the protein and are accessible through an ion well, and that (c) in the $\mathrm{E}_{1}$ conformation binding of $\mathrm{K}^{+}$(or its congeners $\mathrm{Li}^{+}, \mathrm{Rb}^{+}, \mathrm{Cs}^{+}, \mathrm{Tl}^{+}$, and $\mathrm{NH}_{4}^{+}$) is electroneutral, i.e., the binding sites are not buried inside the protein (Goldshlegger et al. 1987; Wuddel and Apell 1995; Domaszewicz and Apell 1999).

As will be shown below, in the case of the SR Ca-ATPase and the gastric H,K-ATPase, all ion binding and release steps are electrogenic, an observation which is in agreement with a position of $\mathrm{Ca}^{2+}$ ions in the $\mathrm{E}_{1}$ conformation of the SR Ca-ATPase inside the membrane-spanning parts of the protein (Toyoshima et al. 2000; Toyoshima and Nomura 2002). Therefore, the generally agreed structural similarity of Na,K-ATPase and SR CaATPase (Sweadner and Donnet 2001; Toyoshima and Nomura 2002) argues that ion binding to the $\mathrm{Na}, \mathrm{K}$-ATPase ought to be electrogenic, not only in the $\mathrm{P}-\mathrm{E}_{2}$ form, as it was proven, but also in $\mathrm{E}_{1}$. However, $\mathrm{K}^{+}$binding in $\mathrm{E}_{1}$ was found to be electroneutral, and only binding of the third $\mathrm{Na}^{+}$ion appeared to be electrogenic (Domaszewicz and Apell 1999; Schneeberger and Apell 2001). This discrepancy may have two possible explanations: (a) the position of the ion binding sites in the Na,K-ATPase is significantly different from that in the SR Ca-ATPase and H,K-ATPase, or (b) the electrogenicity of the binding and release steps in $\mathrm{E}_{1}$ is obscured by simultaneous counter-movement of $\mathrm{H}^{+}$ions. A hint pointing to the second proposal was found in the fact that in the absence of $\mathrm{K}^{+}$and $\mathrm{Na}^{+}$it is possible to phosphorylate the enzyme by $\mathrm{P}_{\mathrm{i}}$ and that the apparent rates of this pathway are $\mathrm{pH}$-dependent. From the analysis of the kinetics it was concluded that the transition $\mathrm{E}_{2}-\mathrm{P}$ $\rightarrow \mathrm{E}_{1}$ occurs with two $\mathrm{H}^{+}$ions bound and the transitions with empty binding sites is either extremely slow or absent (Apell et al. 1996). Recently acquired evidence shows that the missing electrogenicity of $\mathrm{K}^{+}$release and binding of the first two $\mathrm{Na}^{+}$in state $\mathrm{E}_{1}$ can be explained by an obscuring counter-movement of $\mathrm{H}^{+}$ions (Apell and Diller 2002). The obvious ability of the two "non- $\mathrm{Na}^{+}$specific" binding sites to bind two $\mathrm{H}^{+}$ions in $\mathrm{E}_{1}$ with an apparent $\mathrm{pK}$ that is higher than the cytoplasmic $\mathrm{pH}$ under physiological conditions can explain the apparently electroneutral $\mathrm{Na}^{+}$and $\mathrm{K}^{+}$binding or release. These ion-exchange processes result in apparently electroneutral release and binding steps, and maintain, besides a closely related structural relationship, also a mechanistic agreement between $\mathrm{Na}, \mathrm{K}-\mathrm{AT}$ Pase, gastric H,K-ATPase, and SR Ca-ATPase.

Therefore, the biochemically based Post-Albers scheme of the Na,K-ATPase can be expanded as shown in Fig. 7 to explain the transport cycle in greater details. The main difference to the previously proposed pumping mechanism (Apell and Karlish 2001) consists of the placement of all binding sites, as in the case of the SR Ca-ATPase, inside the membrane domains of the protein. Under physiological conditions in conformation $\mathrm{E}_{1}$ the two binding sites, which are able to bind all kinds of monovalent cations, are always occupied, if not by $\mathrm{Na}^{+}$or $\mathrm{K}^{+}$ions then by $\mathrm{H}^{+}$(Apell and Diller 2002). After two $\mathrm{Na}^{+}$ions are bound, the coordination of these ions is assumed to induce a minor conformational rearrangement in the membrane domain, providing access to the third, high-affinity, and $\mathrm{Na}^{+}$-selective 


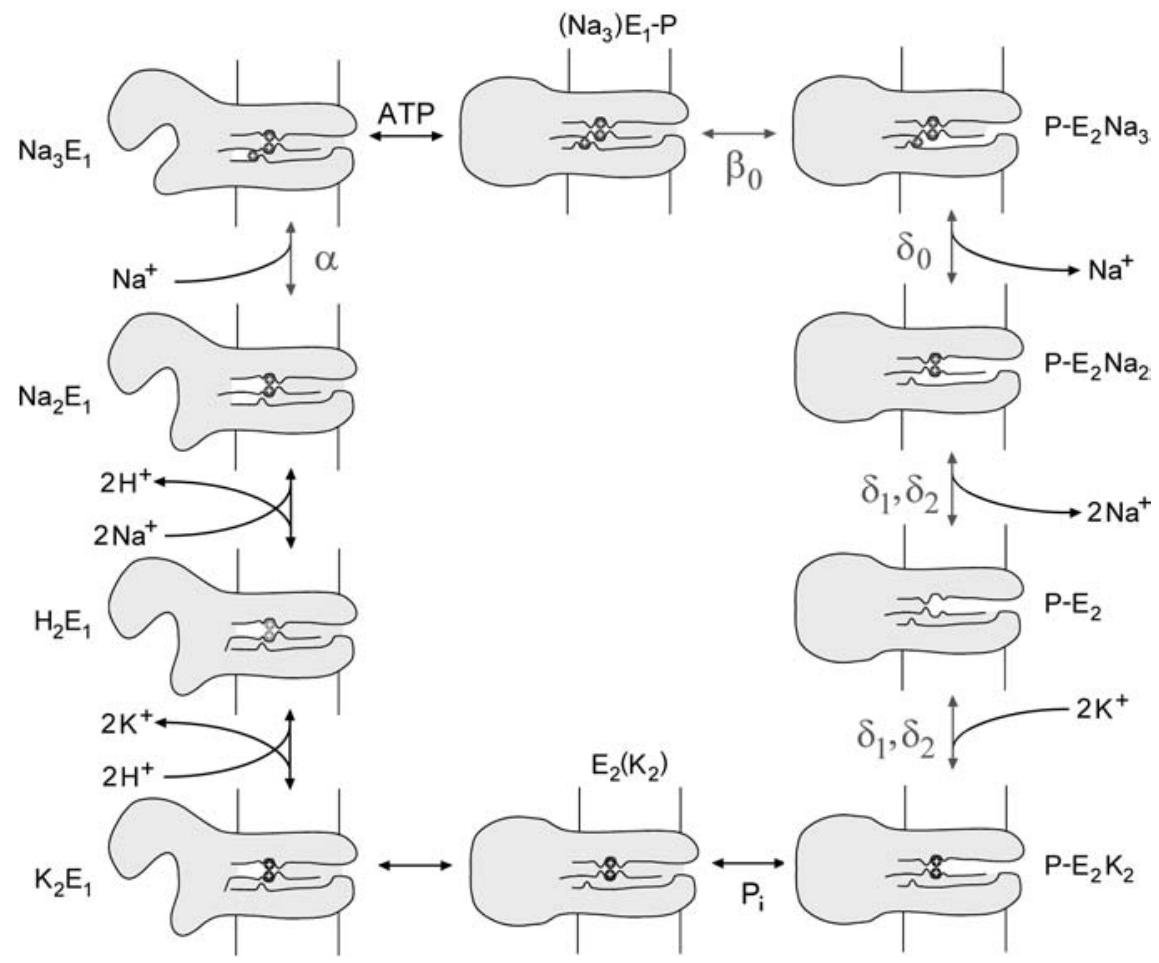

Fig. 7 Refined mechanistic model of the ion transport through the Na,K-ATPase on the basis of the PostAlbers cycle, structural constraints from the Ca-ATPase, and the analysis of charge movements during the transport process. Those reaction steps marked with Greek letters indicate the electrogenic processes that were detected under physiological conditions. The corresponding dielectric coefficients are $\alpha=0.25, \beta<0.1$, $\delta_{0}=0.65, \delta_{1}=\delta_{2}=0.1-0.2$. The apparent electroneutrality (at $\mathrm{pH} 7$ ) of $\mathrm{K}^{+}$release and binding of the first two $\mathrm{Na}^{+}$ions on the cytoplasmic side is caused by a counter movement of two $\mathrm{H}^{+}$ions

site (Schneeberger and Apell 2001) that does bind an $\mathrm{Na}^{+}$(at least under physiological conditions). This step may be accompanied by a so-called preocclusion of the first two $\mathrm{Na}^{+}$ions bound, prohibiting their exchange with the aqueous phase. Binding of the third $\mathrm{Na}^{+}$to its site about $25 \%$ inside the membrane domain is thought to require an additional adaptation of the transmembrane helices to coordinate the ion. This process will affect the $\mathrm{N}$ and/or $\mathrm{P}$ domain leading to enzyme phosphorylation and the conformation transition into state $\mathrm{P}-\mathrm{E}_{2} \mathrm{Na}_{3}$. As in the case of the Ca-ATPase, it can be expected that this major transition $\mathrm{E}_{1} \rightarrow \mathrm{E}_{2}$ moves the $\alpha$-helices of the membrane domain and distorts the coordination of the $\mathrm{Na}^{+}$ions in their sites so that the binding affinities decrease by 2-3 orders of magnitude (Wuddel and Apell 1995). This transition shows only a minor electrogenic charge movement within the membrane domain. Due to the small amplitude of this effect, so far it has not been resolved which charges are moved.

Because of the high dielectric coefficient $(0.65-0.7)$, the first $\mathrm{Na}^{+}$ion released to the extracellular aqueous phase is assumed to be the ion bound last in $\mathrm{E}_{1}$. After its removal, a further structural relaxation is proposed (Hilgemann 1994) which allows the remaining two ions to migrate to the aqueous phase with a significantly smaller dielectric coefficient when compared with the first $\mathrm{Na}^{+}$ion. An intrusion of a number of water molecules would 
be sufficient to increase the local dielectric constant sufficiently to account for the reduction in electrogenicity (Wuddel and Apell 1995).

In the $\mathrm{P}-\mathrm{E}_{2}$ state the $\mathrm{pK}$ of the binding moieties is significantly lower than in $\mathrm{E}_{1}$ so that under physiological $\mathrm{pH}$ no protonation occurs (Apell and Diller 2002). However, the affinity for $\mathrm{K}^{+}$ions is so high in the relaxed $\mathrm{P}-\mathrm{E}_{2}$ state that subsequent $\mathrm{K}^{+}$binding occurs spontaneously and fast in an electrogenic manner (Rakowski et al. 1990). Subsequently, occlusion of the $\mathrm{K}^{+}$ions due to enzyme dephosphorylation and the conformation transition back into $\mathrm{E}_{1}$ (with or without ATP in the low-affinity binding site) occur without detectable electrogenicity. The requirement of two negative counter charges in the binding sites to account for the electroneutrality loses weight when the sites remain inside the membrane domain and are no longer shifted close to the cytoplasmic surface, as was required in the previous functional model. On the basis of the Ca-ATPase structure, the primary role of charged amino acids will be creation of an energetically favorable coordination of the dehydrated ion, i.e., of the structure named binding site(s). In $\mathrm{E}_{1}$ the $\mathrm{K}^{+}$ions are able to exchange freely with the aqueous cytoplasm and charged amino acids in the binding sites are immediately compensated by two $\mathrm{H}^{+}$ions so that a $\mathrm{K}^{+}$release without electrogenic contributions is mimicked.

In summary, the ion-transport mechanism is in agreement with an alternate access model in which the binding sites remain at (almost) the same location and the protein movements open and close the access to these sites alternately on both sides (Läuger 1984).

\section{SR Ca-ATPase}

The purpose of the Ca-ATPase of the sarcoplasmatic reticulum is to promote muscle relaxation by pumping $\mathrm{Ca}^{2+}$ ions back into the lumen of the reticulum. In this action the protein is able to build up a $10^{4}$-fold concentration gradient across the membrane. With respect to the known stoichiometry of $2 \mathrm{Ca}^{2+}$ ions transported per ATP hydrolyzed, this process is energetically possible only by the fact that no electric potential is generated across the SR membrane. This is made secure in part by counter-transport of $2 \mathrm{H}^{+}$but mainly by a high leak conductance of the membrane for ions other than $\mathrm{Ca}^{2+}$.

As pointed out recently, the snapshots of the SR Ca-ATPase structure in its two basic conformations are a major step in the understanding of pump dynamics of P-type ATPases (Green and MacLennan 2002). Unfortunately, a direct analysis of the transport functions of this ion pump is almost impossible. Due to the mentioned leak conductance of the SR membrane, it is electrically short-circuited, and only processes with time constants short against the RC time of the SR-vesicle membrane may be detected. Therefore, it was difficult to determine the existence of $\mathrm{H}^{+}$counter-transport by the pump (Madeira 1978; Chiesi and Inesi 1980), and only after reconstitution of the Ca-ATPase in lipid vesicles (Cornelius and Møller 1991) a proof of counter-transport and of electrogenicity was provided (Yu et al. 1993, 1994). The application of three different fluorescent dyes to detect membrane potential as well as luminal $\mathrm{pH}$ and $\mathrm{Ca}^{2+}$ concentration demonstrated a stoichiometry of $2 \mathrm{Ca}^{2+} / 2 \mathrm{H}^{+} / 1$ ATP (Fig. 8). To resolve the electrogenicity of the different reaction steps of the pump cycle, experiments had to be performed with a styryl dye, 2BITC, which showed that $\mathrm{Ca}^{2+}$ and $\mathrm{H}^{+}$binding and release were accompanied by significant charge movements in the membrane domain (Butscher et al. 1999; Peinelt and Apell 2002). These findings meet the requirements of the position of the ion binding sites of the Ca-ATPase as predicted by the crystal structure of the protein. Kinetical studies of partial reactions in the pump 


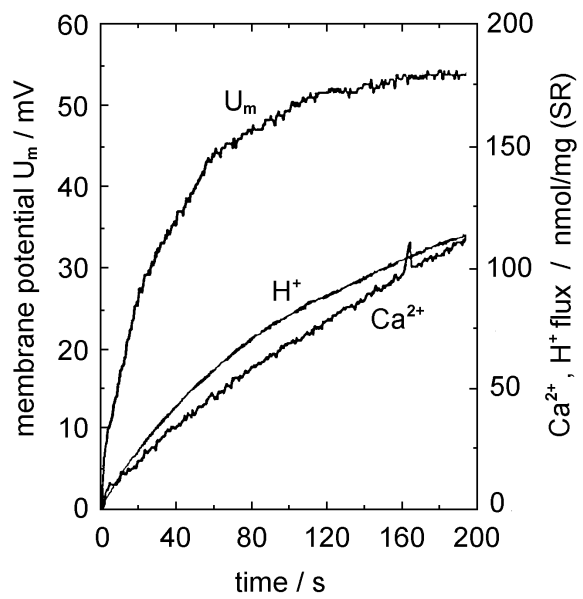

Fig. 8 ATP-dependent $\mathrm{Ca}^{2+}$ uptake, $\mathrm{H}^{+}$counter transport, and development of transmembrane electrical potential at low temperature. (From Yu et al. 1994, with kind permission). SR Ca-ATPase was reconstituted in lipid vesicles. ATP-induced pump activity was detected with fluorescence dyes: The time course of the membrane potential was detected with oxonol VI, the luminal $\mathrm{pH}$ with pyranine, and the luminal $\mathrm{Ca}^{2+} \mathrm{Con}^{-}$ centration with arsenazo III. The stoichiometric parallelism of $\mathrm{Ca}^{2+}$ uptake and $\mathrm{H}^{+}$extrusion is obvious and the voltage increase at low transmembrane electric potentials (when leakage effects are small) is also in agreement with estimations from the amounts of ions transferred

cycle were already performed by analysis of the enzymatic properties many years ago (Andersen and Vilsen 1988; Inesi and de Meis 1989; Inesi et al. 1992). Due to the high leak conductance of the SR membrane, time-resolved measurements are scarce. Studies with radioisotopes and/or quenched flow provided some insight into rate constants for single reaction steps (Froehlich and Heller 1985; Orlowski and Champeil 1991), and capacitive coupling of SR membrane vesicles to a planar lipid bilayer provided some information on the rate-limiting reaction steps in the $\mathrm{Ca}^{2+}$ and $\mathrm{H}^{+}$transfer (Hartung et al. 1997). A systematic analysis of the kinetical properties beyond early estimations (Inesi and de Meis 1989) is not available so far. Recently, it was shown that the application of styryl dyes may be used similarly successfully to study the time-resolved kinetical behavior of SR CaATPase (Peinelt and Apell 2003). So far, all experimental findings are in agreement with a Post-Albers cycle equivalent to that of the Na,K-ATPase (Fig. 3), in which $3 \mathrm{Na}^{+}$ions are to be replaced by $2 \mathrm{Ca}^{2+}$ and $2 \mathrm{~K}^{+}$ions by $2 \mathrm{H}^{+}$.

\section{Gastric H,K-ATPase}

The gastric H,K-ATPase is enriched in the parietal cells of the gastric glands of the stomach which perform secretion of hydrochloric acid upon hormonal stimulation. The active part in this process is $\mathrm{H}^{+}$extrusion from the cytoplasm while, by opening of passive $\mathrm{Cl}^{-}$ and $\mathrm{K}^{+}$pathways, both ion species are released, and $\mathrm{K}^{+}$is reabsorbed in exchange for the $\mathrm{H}^{+}$so that eventually $\mathrm{HCl}$ is concentrated up to $\mathrm{pH} 1-1.5$ in the stomach.

The reaction cycle of this P-type pump is also well reproduced by the Post-Albers cycle shown in Fig. 3, in which the $\mathrm{Na}^{+}$-dependent half-cycle has to be replaced by an $\mathrm{H}^{+}$transporting part (with $2 \mathrm{H}^{+}$ions per ATP hydrolyzed). Like in the case of the Na,K-AT- 

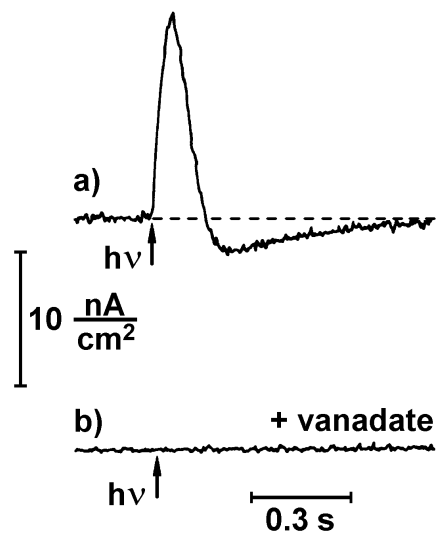

Fig. 9a, b ATP-induced $\mathrm{H}^{+}$current through gastric $\mathrm{H}, \mathrm{K}-\mathrm{ATPase}$ in membrane vesicles isolated from pig stomach. (From van der Hijden et al. 1990). a Buffer contains, besides $\mathrm{H}^{+}$ions (pH 6), no other monovalent cations. The arrows indicate the time when light was switched on to release $\sim 10 \mu \mathrm{M}$ ATP from caged ATP. The concentration jump triggered the partial reaction $\mathrm{H}_{2} \mathrm{E}_{1}+\mathrm{ATP} \rightarrow \mathrm{P}-\mathrm{E}_{2}+2 \mathrm{H}^{+}+\mathrm{ADP}$. The positive current transient represents an inward-oriented flux of positive charge. b Inhibition of the pump by $200 \mu \mathrm{M}$ vanadate abolished-as expected—any electric current transient upon ATP release from caged ATP

Pase, the two principal enzyme conformations could be identified (Helmich-de Jong et al. 1987), and the stoichiometry was found to be $2 \mathrm{H}^{+} / 2 \mathrm{~K}^{+} / 1$ ATP (Faller et al. 1982). The resulting overall electroneutrality leads to experimental difficulties in the performance of detailed studies of the ion transport by the H,K-ATPase. The fact that in each half-cycle of the pumping scheme two monovalent cations traverse the membrane has to result in a detectable electrogenic contribution when $\mathrm{H}^{+}$or $\mathrm{K}^{+}$transport are investigated separately. Fig. 9 shows a unambiguous proof that the ATP-induced $\mathrm{H}^{+}$transfer, $\mathrm{H}_{2} \mathrm{E}_{1}+\mathrm{ATP} \rightarrow \ldots \rightarrow$ $\mathrm{P}_{-} \mathrm{E}_{2}+2 \mathrm{H}^{+}$lum $+\mathrm{ADP}$, is accompanied by charge movement (van der Hijden et al. 1990). In these experiments, ATPase-containing vesicles prepared from pig stomach were capacitively coupled to a planar bilayer membrane, and enzyme phosphorylation was triggered by a flash-induced release of ATP from caged ATP. Corresponding experiments for the $\mathrm{K}^{+}$transporting branch of the pump cycle were not possible. Detailed time-resolved kinetical analyses beyond these data of van der Hijden and collaborators are still scarce (Stengelin et al. 1993).

In recent experiments, in which the styryl dye RH421 was applied to detect charge movements, the ion-binding sites were titrated with $\mathrm{H}^{+}$and $\mathrm{K}^{+}$ions in both principal conformations. In these experiments it could be shown that all binding and release steps are electrogenic, while enzyme phosphorylation by ATP produced no significant charge movement within the protein (Diller et al. 2003).

\section{Energetic properties}

Important for the understanding of the ion transport in ion pumps are, besides structural knowledge and kinetical properties, considerations on the energetics of transport. The knowledge of the "costs" in terms of free-enthalpy changes of the various reaction steps 


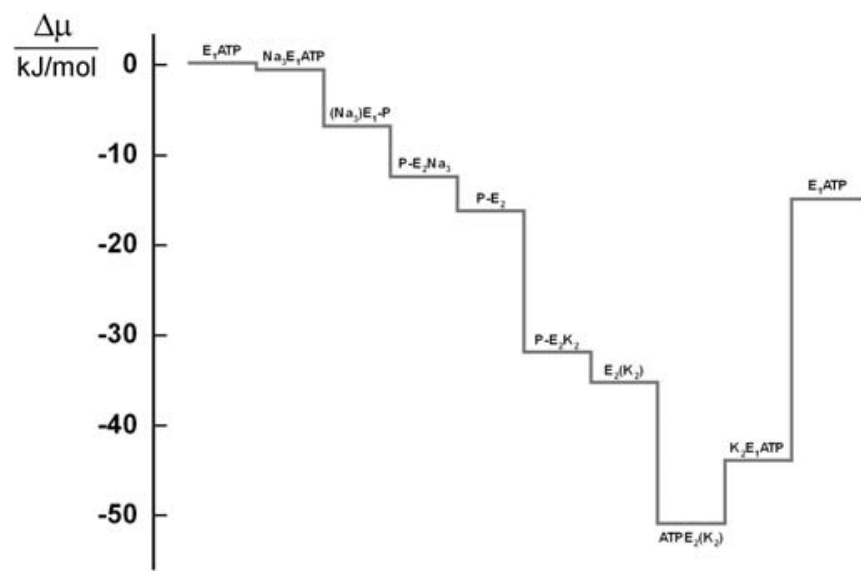

Fig. 10 Free energy levels of the individual states in the Na,K-ATPase pump cycle (Fig. 3). The energy levels were calculated according to Läuger (1991) on the basis of the kinetical parameters of Apell (1997). All levels refer to state $\mathrm{E}_{1}$. ATP as reference state

around the pump cycle provides at least clues to underlying processes which affect the protein structure and which facilitate the observed pump action.

Free energy levels

T.L. Hill showed that energy transduction in molecular machines like P-type ATPase is not the result of a single reaction step but of the cycle as a whole (Hill 1977, 1989). It is an interesting question, however, to what extent single reaction steps contribute to storage and consumption of the system's free energy. To gain access to such information, energy levels must be introduced for all the states of the pumping cycle which are long-lived states on the time scale of molecular motions and which are in equilibrium with respect to movements of the peptide backbone or amino acid side chains. Accordingly, the states can be treated as chemical species with a well-defined chemical potential which were introduced for those defined states of the ion pumps as "basic free energy levels" (Hill 1977). As has been shown earlier, the differences of free energy between two consecutive states can be determined from the forward and backward rate constants of the transition, or the corresponding equilibrium constant (Läuger 1991).

Analyses of free basic energy levels have been performed for ion pumps on a general level (Läuger 1984), for the SR Ca-ATPase on the basis of a less elaborate data base (Walz and Caplan 1988), and also for the Na,K-ATPase in great detail (Stein 1990; Apell 1997). Free basic energy calculations can be performed for all states around the Post-Albers cycle. Placing state $\mathrm{E}_{1}$ ATP (cf. Fig. 3) as initial level arbitrarily to zero, the sequence of states around the pumping cycle in the physiological mode led to a lower level after a cycle is completed (Fig. 10). For the sake of simplicity, the free energy gained by binding of ATP (in step $E_{2}\left(K_{2}\right) \rightarrow E_{2}\left(K_{2}\right)$ ATP) is not implemented in this figure. If the energy difference between two successive states is near zero, the distribution between both states is close to its thermodynamic equilibrium. If the energy difference is negative, the reaction runs "downhill," i.e., it is dissipating energy; a positive energy difference indicates energy 
storage, either in the protein conformation or in the electrochemical potential difference between bulk phase and binding site(s) for the involved ion species.

Of special functional importance in the diagram shown in Fig. 10 is the free-energy decrease by enzyme phosphorylation and the subsequent conformational change, $\mathrm{Na}_{3} \mathrm{E}_{1} \cdot \mathrm{ATP}$ $\rightarrow\left(\mathrm{Na}_{3}\right) \mathrm{E}_{1}-\mathrm{P} \rightarrow \mathrm{P}-\mathrm{E}_{2}\left(\mathrm{Na}_{3}\right)$, which effectively drains the states which bind $\mathrm{Na}^{+}$ions from the cytoplasm, thus producing dynamically the observed higher apparent affinity for $\mathrm{Na}^{+}$ than for $\mathrm{K}^{+}$ions in state $\mathrm{E}_{1}$, despite the values determined by steady-state titration experiments (Schneeberger and Apell 2001). Other significant "downhill" reaction steps are extracellular $\mathrm{K}^{+}$binding, $\mathrm{P}-\mathrm{E}_{2} \rightarrow \mathrm{P}-\mathrm{E}_{2} \mathrm{~K}_{2}$, and ATP binding, $\mathrm{E}_{2}\left(\mathrm{~K}_{2}\right) \rightarrow$ ATP $\cdot \mathrm{E}_{2}\left(\mathrm{~K}_{2}\right)$. In both cases the decrease of free energy is caused by ligand concentrations far above their affinities (which are $\sim 0.1 \mathrm{mM}$ for $\mathrm{K}^{+}$and $8 \mu \mathrm{M}$ for ATP). A reduction of ligand concentrations would diminish the step size. This is true also in the most prominent "uphill" reaction, the $\mathrm{K}^{+}$release step in partial reaction $\mathrm{K}_{2} \mathrm{E}_{1} \cdot \mathrm{ATP} \rightarrow \mathrm{E}_{1}$. ATP, in which the ions face a high cytoplasmic concentration of $150 \mathrm{mM}$ from binding sites which have an affinity on the order of $0.1 \mathrm{mM}$. However, under turnover conditions $\mathrm{K}^{+}$release is not rate limiting because of the high rate constants of all ion release and binding steps in the reaction sequence $\mathrm{K}_{2} \mathrm{E}_{1}$. ATP $\rightarrow \ldots \rightarrow \mathrm{Na}_{3} \mathrm{E}_{1}$. ATP so that it may be assumed to be in a dynamic equilibrium.

The effect of the actual ion concentrations on the energetics is extremely high in the case of the SR Ca-ATPase. In a contracted muscle, the ratio of the $\mathrm{Ca}^{2+}$ concentrations across the SR membrane is in the order of 50; in the relaxed muscle it is in the order of 30,000 . When the free energy of transport is calculated under these conditions according to:

$\Delta G_{\text {transp }}=\Delta \tilde{\mu}_{\mathrm{Ca}}=2 R T \ln \frac{\left[\mathrm{Ca}^{+}\right]_{\text {lum }}}{\left[\mathrm{Ca}^{+}\right]_{\mathrm{cyt}}}$

one obtains $\sim 20 \mathrm{~kJ} / \mathrm{mol}$ (contracted state) and $\sim 53 \mathrm{~kJ} / \mathrm{mol}$ (relaxed state), assuming that there is no $\mathrm{pH}$ gradient across the membrane. These numbers have to be compared to the Gibbs Free Energy of ATP hydrolysis, $-\Delta G_{\mathrm{ATP}}$, which was found to be $\sim 63 \mathrm{~kJ} / \mathrm{mol}$ in rat muscle (Meyer et al. 1982). The energy efficiency, $\mid \Delta G_{\text {trans }} / \Delta G_{\text {ATP }}$, derived from these numbers increases from $32 \%$ to $84 \%$ when $\mathrm{Ca}^{2+}$ is stored back in the sarcoplasmatic reticulum. In the case of the $\mathrm{Na}, \mathrm{K}$-ATPase, the ion-concentration changes in the cytoplasm are not significant and the efficiency (at a membrane potential of $-70 \mathrm{mV}$ ) is always around $70 \%$.

However, the free-energy balance of the ATPases is not only affected by the ion concentrations, but also by their electrogenicity. Those partial reactions in the cycle which have been found to be electrogenic, i.e., especially ion binding and release steps, have rate constants (or equilibrium dissociation constants) which depend on the membrane potential and, as a consequence, their basic free energy levels can be modulated by the membrane potential (Läuger and Apell 1986; Apell 1997).

\section{Temperature dependency}

Another way to get information on the energetics of the ion pumps is from the temperature dependence of protein function. According to a description by Arrhenius, the activation energy for a chemical reaction, $E_{\mathrm{a}}$, can be introduced by the empirical relation 
Table 1 Energetics of selected reaction steps from rabbit kidney Na,K-ATPase. Enthalpy $\mathrm{H}^{\dagger}$ and Entropy $\mathrm{S}^{\dagger}$ were calculated from experimentally determined rate constants applying the theory of absolute reaction rates (unpublished data)

\begin{tabular}{lcl}
\hline $\begin{array}{l}\text { Rate limiting step } \\
\text { of the reaction sequence }\end{array}$ & $\begin{array}{l}\text { Enthalpy } \mathrm{H}^{\dagger} \\
\text { in } \mathrm{kJ} / \mathrm{mol}\end{array}$ & $\begin{array}{l}\text { Entropy } \mathrm{S}^{\dagger} \\
\left.\text { in J/mol K (at } 25^{\circ} \mathrm{C}\right)\end{array}$ \\
\hline $\mathrm{Na}_{2} \mathrm{E}_{1} \rightarrow \mathrm{Na}_{3} \mathrm{E}_{1}$ & $\sim 20$ & -227 \\
$\mathrm{Na}_{3} \mathrm{E}_{1} \rightarrow \mathrm{Na} \mathrm{E}_{1} \cdot \mathrm{ATP}$ & 52 & -226 \\
$\mathrm{Na}_{3} \mathrm{E}_{1} \cdot \mathrm{ATP} \rightarrow\left(\mathrm{Na}_{3}\right) \mathrm{E}_{1}-\mathrm{P}$ & 64 & -224 \\
$\left(\mathrm{Na}_{3}\right) \mathrm{E}_{1}-\mathrm{P} \rightarrow \mathrm{P}-\mathrm{E}_{2} \mathrm{Na}_{3}$ & 112 & -219 \\
$\mathrm{P}-\mathrm{E}_{2} \mathrm{~K}_{2} \rightarrow \mathrm{E}_{2}\left(\mathrm{~K}_{2}\right)$ & 65 & -224 \\
$\mathrm{E}_{2}\left(\mathrm{~K}_{2}\right) \rightarrow \mathrm{E}_{2}\left(\mathrm{~K}_{2}\right) \cdot \mathrm{ATP}$ & 70 & -224 \\
$\mathrm{E}_{2}\left(\mathrm{~K}_{2}\right) \cdot \mathrm{ATP} \rightarrow \mathrm{K}_{2} \mathrm{E}_{1} \cdot \mathrm{ATP}$ & 66 & -224 \\
\hline
\end{tabular}

$k=A \cdot \exp \left(-\frac{E_{\mathrm{a}}}{R T}\right)$

and determined from the slope of a so-called Arrhenius plot. Although we do not have a one-step reaction, but a cyclic reaction sequence in the ATPases, it is still possible, for example, to plot the hydrolyzing activity of the Na,K-ATPase in an Arrhenius plot (Apell 1997). However, the interpretation is not straightforward. There are good arguments to claim that the apparent activation energy is mainly that of the rate limiting step in the observed process. Therefore, it is possible that the Arrhenius plot may be bent when processes with different activation energy become rate limiting in the low and high temperature range and take over control of the scrutinized partial reaction (Apell 1997).

Instead of using the empirical concept of Arrhenius from the nineteenth century, which results in an activation energy representing approximately the height of the potential energy barrier of the rate-limiting reaction step, an alternative concept can be used. The theory of absolute reaction rates describes the rate constant of a reaction as a function of thermodynamically well-defined energies (Moore and Pearson 1981):

$k=\frac{k_{B} T}{h} \cdot \exp \left(-\frac{G^{\dagger}}{R T}\right)=\frac{k_{B} T}{h} \cdot \exp \left(\frac{S^{\dagger}}{R}\right) \cdot \exp \left(-\frac{H^{\dagger}}{R T}\right)$

This theory allows a determination of the contributions of entropy $\mathrm{S}^{\dagger}$ and enthalpy $\mathrm{H}^{\dagger}$ to a reaction step. With the assumption that the transition state is in equilibrium with the ground state, it is possible to draw the same conclusions from the magnitude of $\mathrm{S}^{\dagger}$ and $\mathrm{H}^{\dagger}$ on structural changes during a partial reaction as one can get from thermodynamic parameters of overall reactions.

The reaction steps of the Na,K-ATPase occur in an aqueous environment and, therefore, entropy changes are dominated by binding and release of water molecules or ions. If a negative entropy change is observed, it is caused mainly by immobilization of solvent molecules or ions in the protein. From so far unpublished experiments in our lab, $\mathrm{S}^{\dagger}$ and $\mathrm{H}^{\dagger}$ were determined for a number of partial reactions (Table 1). These are recent results and the project is still under development. However, it is obvious that only in one of the reaction steps which are accessible so far, a significantly higher enthalpy, $\mathrm{H}^{\dagger}$, was determined: in the conformation transition from $\mathrm{E}_{1}$ to $\mathrm{E}_{2}:\left(\mathrm{Na}_{3}\right) \mathrm{E}_{1}-\mathrm{P} \rightarrow \mathrm{P}-\mathrm{E}_{2} \mathrm{Na}_{3}$. This step was also found to be the rate-limiting step in the $\mathrm{Na}^{+}$transport branch of the pump cycle. Re- 
markable also is the finding that the entropy changes in all steps analyzed are approximately the same, on the order of $-225 \mathrm{~J} / \mathrm{molK}$, indicating that there exists no process in which more energy is "wasted" than in others.

The information which we hope to obtain finally from the thermodynamic properties of the pump process, namely from basic free energies, changes of entropy and enthalpy, will provide constraints for mechanistic models and support the development of microscopic descriptions of protein functions as well as of the coupling of enzymatic activity and transport.

\section{Probing crucial amino acids}

Before the structure of the SR Ca-ATPase became known, the most important tool to obtain information on structure-function relations was the investigation of pump proteins modified by mutagenesis. Numerous laboratories studied effects on enzymatic or transport properties of the ATPases which could be detected after an exchange of amino acids. By this technique, parts of the protein could be identified which are crucial for substrate binding, transport, or conformational changes. Such studies were performed with the SR CaATPase in order to pin down amino acids involved in $\mathrm{Ca}^{2+}$ binding sites (Clarke et al. 1989a, Andersen 1995; Vilsen 1995) and these were eventually confirmed by the structure of the crystallized protein (Toyoshima et al. 2000). It was found that the two $\mathrm{Ca}^{2+}$ binding sites were formed by the side-chain oxygen atoms of Asn 768, Glu 771, Thr 799, Asp 800, and Glu 908 as site I and by Asn 796, Asp 800, Glu 309, and the main chain carbonyl oxygen atoms of Val 304, Ala 305, Ile 307 as site II. To couple ion-transport in/through the membrane domain and enzymatic activity in the $\mathrm{N}, \mathrm{P}$, and A domains, the cytoplasmic loop L67 between helix M6 and M7 also plays an important role.

In the case of other P-type ATPases, especially the Na,K-ATPase and H,K-ATPase, for which extensive functional studies are available, structural similarities to the Ca-ATPase may be exploited to identify elements specific for transport function (Sweadner and Donnet 2001). However, such comparisons should be used preferentially as a basis for conceptual considerations and to scout purposeful point mutations.

The era of mutagenesis as an investigative tool began after the sequences of ion pumps became available (Shull et al. 1985, 1988) and within a short period of time the number of contributions almost exploded. As expression systems for the mutated sequence, several assays are applied: cRNA injection into Xenopus oocytes is very useful for electrophysiological studies (Horisberger et al. 1991; Vasilets et al. 1991), while for biochemical studies overexpression of ATPases in yeast (Scheiner-Bobis and Farley 1994; Pedersen et al. 1996) or insect cell lines (Blanco et al. 1995; Gatto et al. 2001) is convenient. In such cell lines the use of a baculovirus infection system was very successful for the examination of the H,K-ATPase (Klaassen et al. 1993) and the Na,K-ATPase (Gatto et al. 2001).

A recent review on established structure-function relationships through site-directed mutagenesis (Jørgensen and Pedersen 2001) showed that in the transmembrane segments M4, M5, and M6 of the $\alpha$ subunit, at least nine amino acids could be identified which are important for binding of $\mathrm{Na}^{+}, \mathrm{K}^{+}$, or $\mathrm{Tl}^{+}$. Most of them are homologous counterparts of the side chains which form the $\mathrm{Ca}^{2+}$ binding sites in the SR Ca-ATPase. In the yeast expression system with a renal $\alpha_{1} \beta_{1} \gamma$ enzyme, the crucial amino acids were: Glu 327, Asn 776, Glu 779, Asp 804, Thr 807, and Asp 808. Other amino acids could be shown to affect the dissociation constants for $\mathrm{Mg}^{2+}$ and ATP (Jørgensen and Pedersen 2001). The fifth and 
sixth transmembrane domains were also recently investigated by cysteine-scanning mutagenesis, another powerful tool to identify the role of single amino acids (Guennoun and Horisberger 2000, 2002).

Mutagenesis studies were also performed with the H,K-ATPase to determine amino acids in the transmembrane segments that are involved or affect ion binding and transport (Hermsen et al. 2000, 2001; Asano et al. 2001; Rulli et al. 2001). In transmembrane domains M4, M5, and M6, four conserved, negatively charged amino-acid side chains were found which are important for ion binding and thus for the pumping process: Glu 343, Glu 795, Glu 820, and Asp 824 (Sequence according to Shull and Lingrel 1986). It could be demonstrated that a replacement of Glu 795 and Glu 820 by uncharged amino acid side chains resulted in a phenotype with a constitutive ATPase activity in the absence of $\mathrm{K}^{+}$ ions. It was suggested that the absence of the two negatively-charged side chains mimics an occupation of the ion binding sides by $\mathrm{K}^{+}$ions, the state which would be the trigger for enzyme dephosphorylation in the wild-type enzyme (Hermsen et al. 2001). In M6, an additional amino acid was identified that also affects $\mathrm{K}^{+}$-dependent dephosphorylation, Leu 817 (Asano et al. 2001).

A demonstration of the close relationship of Na,K-ATPase and gastric H,K-ATPase is made visible in chimera of both ion pumps. In a recent paper it was shown that substitution of three residues in the M4 segment of the Na,K-ATPase sequence with their H,KATPase counterparts (Leu319Phe, Asn326Tyr, Thr340Ser) and replacing the M3-M4 loop sequence with that of the H,K-ATPase $\alpha$-subunit results in a protein that exhibits $50 \%$ of its maximal ATPase activity in the absence of $\mathrm{Na}^{+}$ions when the assay is performed at pH 6.0 (Mense et al. 2002). Twenty-one of the 29 amino acids that are thought to form M4 are already identical in both ATPases.

A different approach to test amino acids and their close environment is the application of specific oxidative cleavage mediated by Fenton chemistry with complexed transition metal ions, such as $\mathrm{Fe}^{2+}$ complexed by ATP or $\mathrm{Cu}^{2+}$ by 4,7-diphenyl-1,10-phenantroline (Goldshleger et al. 2001; Tal et al. 2001). With this method a region of interaction between the $\alpha$ and $\beta$ subunits of the Na,K-ATPase could be identified, and short sequences of four amino acids in transmembrane helices M1 and M3 that are in proximity to each other near the cytoplasmic surface. Applying this technique to the H,K-ATPase led to results essentially identical to that for Na,K-ATPase (Shin et al. 2001).

\section{Comparisons of transport mechanism of SR Ca-ATPase, Na,K-ATPase and H,K-ATPase}

Stimulated by the 3D structure of the SR Ca-ATPase, the close relation between P-type ATPases is discussed to a great extent, especially for the three most prominent pumps, SR $\mathrm{Ca}-\mathrm{ATPase}, \mathrm{Na}, \mathrm{K}-\mathrm{ATPase}$, and $\mathrm{H}, \mathrm{K}-\mathrm{ATPase}$. The most recent overview of this field will be published in 2003 as a special volume of the Annals of the New York Academy of Sciences, containing the Proceedings of the 10th International Conference on Na,K-ATPase and Related Cation Pumps, vol. 986 (2003).

Summarizing the above-discussed findings in this presentation, it can be proposed that the high homology in amino-acid sequence and, most probably, a high similarity of the quaternary structure of the three ATPases, is complemented by a single concept of the transport mechanism which allows a description of all transport phenomena observed so 
Fig. 11 Schematic representation of the ion transport pathway and ion binding sites in P-type ATPases. Access to the binding sites from the aqueous phases is controlled by gates that alternate in opening the pathway. The pump is in an occluded state when both gates lock the access channels. An open state of both gates would produce an ion-channel like behavior and is prohibited under physiological conditions

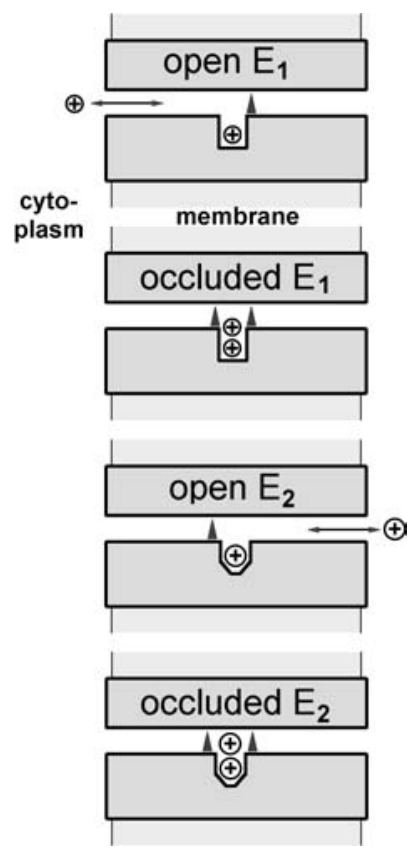

far. This concept is based on an alternate-access channel model discussed first by P. Läuger (Läuger 1979). The main features of the adapted mechanism are illustrated in Fig. 11, and they include (a) narrow access channels from both sides, (b) one gate per access channel, and (c) an ion binding moiety that is adapted specifically and differently in both principal conformations to the ions that are transported.

The transmembrane part of the pump, which is formed by ten helices of the $\alpha$ subunit and by the $\beta$ subunit, is represented in Fig. 11 as a shaded box with a cavity inside the membrane. The cavity is connected to the bulk phase on both sides by narrow access channels. Each half channel possesses a gate that is controlled by the protein conformation (including changes induced by ATP binding and protein phosphorylation/dephosphorylation). A consequence of this arrangement is that ion binding and release is electrogenic on both sides. Such an electrogenicity was found for all three ion pumps, although in the case of the Na,K-ATPase the electrogenicity of cytoplasmic $\mathrm{K}^{+}$binding is hidden by transient $\mathrm{H}^{+}$ binding (see the section entitled "Detailed ion transport mechanism"). With this finding the previously formulated constraint that the binding sites have to be twofold negatively charged is no longer strictly necessary. Nevertheless, negative (partial) charges in the binding sites are required to coordinate the dehydrated cations and to reduce the electric field of the cations in the largely nonpolar interior of the transmembrane part of the pump proteins.

The gates that block ion exchange between sites and aqueous phase are not necessarily mechanical barriers like floodgates. A look at the $3 \mathrm{D}$ structure of the crystallized $\mathrm{Ca}_{2} \mathrm{E}_{1}$ conformation of the Ca-ATPase reveals that there is indeed no steric obstacle in the pathway of the ions. Therefore, the gates which block the access channels have to be thought of as energy barriers produced by an arrangement of amino-acid side chains that do not allow dehydrated ions to be coordinated and thus make ion propagation energetically ex- 
tremely unfavorable. In the $\mathrm{E}_{1}$ states, the right-hand gate in the illustration in Fig. 11 is closed and access for ions is possible only from the cytoplasmic side. Correspondingly, in the states of $E_{2}$ the left gate is closed and ions can enter the binding sites only from the luminal (or extracellular) phase. The occluded states are transient states when the pumps run through their transport cycle and switch back and forth between both principal conformations. Occluded states are characterized by locking the binding moiety from both access channels. They are required to prevent ion-channel-like conformations that would shortcircuit both aqueous phases. (Assuming that a pump transports typically 100 ions per second and an ion channel $10^{7}$ ions per second, then a channel opening of about $10 \mu$ s would destroy the work of $1 \mathrm{~s}$ of pumping). However, under "unphysiological conditions" a channel-like behavior of the Na,K-ATPase could be produced by addition of Palytoxin, a potent marine toxin isolated from Palythoa toxica. In the presence of this compound, electric current fluctuations through the Na,K-ATPase were observed like those of a "classic" ion channel, with fluxes on the order of $10^{6}$ ions per second (Artigas and Gadsby 2003). Because the channel behavior disappears when ATP is washed out, the channel-like behavior is not a consequence of an irreversible protein denaturation, but rather an induced and simultaneous opening of both gates.

The third feature of the mechanistic model is the binding moiety deep inside the membrane domain. In the case of the Ca-ATPase it was found to be inside about $30 \%-40 \%$ of the membrane thickness from the cytoplasmic surface (Toyoshima and Nomura 2002). In this moiety, ion-binding sites are formed in a way that they show differently high binding affinities for the transported ions in both principal conformations. In the case of the SR Ca-ATPase it can be seen that the low $\mathrm{Ca}^{2+}$ affinity $\mathrm{E}_{2}$ (TG) state is produced by a severe disruption of the ion-coordination (cf. the section entitled "Structural properties"). A corresponding change may be proposed to occur by the conformation transition of the $\mathrm{Na}, \mathrm{K}$ ATPase, since an increase of the half-saturating $\mathrm{Na}^{+}$concentration was observed from $\sim 7 \mathrm{mM}$ (in $\mathrm{E}_{1}$ ) to $\sim 400 \mathrm{mM}$ (in $\mathrm{P}-\mathrm{E}_{2}$; Heyse et al. 1994). After dissociation of the $\mathrm{Na}^{+}$ ions, the moiety forming the binding-sites is thought to relax into a new equilibrium that is able to coordinate $2 \mathrm{~K}^{+}$ions with high affinity $\left(K_{1 / 2} \approx 0.1 \mathrm{mM}\right)$ (Bühler and Apell 1995).

When $\mathrm{H}^{+}$ions are bound to these pumps instead of hydronium ions $\left(\mathrm{H}_{3} \mathrm{O}^{+}\right)$, the formation of a complex binding site with an up to sixfold coordination is not necessary; $\mathrm{H}^{+}$may bind to a single carboxylate anion of an amino-acid side chain. Therefore, "real" binding sites have be formed not necessarily for the P-E $\mathrm{E}_{2} \rightarrow \mathrm{E}_{1}$ branch of the SR Ca-ATPase and for the $\mathrm{E}_{1} \rightarrow \mathrm{P}-\mathrm{E}_{2}$ branch of the H,K-ATPase. In Fig. 11 the different affinity for ions in the binding sites is indicated by the shape of the center cavity in the illustration.

\section{Coupling of energetics and transport}

An understanding of the transport mechanism of ion-translocating proteins, such as bacteriorhodopsin, the cytochrome-c oxidase, and the $\mathrm{F}_{0} \mathrm{~F}_{1}$-ATPase was gained after functional observations and kinetic analyses could be correlated with structural information at atomic resolution. For example, studies on bacteriorhodopsin revealed how structural transitions of the chromophore, following absorption of a photon (energy uptake), induce a movement of the Schiff's base, which is used, in a precisely tailored surrounding, to transfer a proton across the central energy barrier in the transport pathway (Haupts et al. 1999; Lanyi and Luecke 2001). Recently, convincing proof was given that a mechanical movement of pro- 
tein subunits, which form a rotor interacting with other parts of the $\mathrm{F}_{0} \mathrm{~F}_{1}$-ATPase, are able to synthesize ATP by a "downhill" movement of protons through the $\mathrm{F}_{0}$ unit or to pump protons "uphill" at the expense of ATP hydrolysis (Senior et al. 2002; Gaballo et al. 2002). In these cases, concepts of well-known macroscopic machines, like a mechanic pump or a water-driven mill, can be used, when scaled down, to describe for these highly specific machines dimensions of a few nanometers.

In the case of the P-type ATPases, such a comprehensive understanding is still lacking. Although structural details are now becoming available, as well as growing insight into functional properties on the basis of biophysical and biochemical studies as presented above, nevertheless, a convincing mechanistic concept of the energy transduction has not been formulated so far. However, ion pumps need not necessarily work as a scaled-down version of known macroscopic machines.

So far, a purely speculative concept can be based on the fact that both known conformations of the enzymatic part of the pump proteins, formed by the N, P, and A domains, switch between two shapes (Fig. 1), one similar to an open boxing-glove ( $\left.E_{1}\right)$ and the other to a closed one $\left(\mathrm{E}_{2}\right)$ that surrounds (under physiological conditions) the $\mathrm{Mg}-\mathrm{P}_{\mathrm{i}}$ complex. In this "glove" the P domain represents the palm, the A domain the thumb, and the $\mathrm{N}$ domain the four fingers. And like the opening and closing of a fist requires movements of muscles and tendons in the forearm, the helices in the transmembrane part of the pump protein will move correspondingly with changes in the cytoplasmic domains. Driving forces for the propagation around the pumping cycle could be a series of substrate-protein interactions in which a binding/dissociation step produces transition states with an enhanced energy (by deformed electron orbitals) that relax by a conformational rearrangement into the next quasi-equilibrium state, ready for another substrate interaction. Such a mechanism is postulated, for example, in case of the $\mathrm{Na}, \mathrm{K}-\mathrm{ATPase}$, where binding of the third $\mathrm{Na}^{+}$ion in $\mathrm{E}_{1}$ acts as a trigger mechanism for enzyme phosphorylation (Schneeberger and Apell 1999).

However, the explicit energetics of P-type reveal, insofar as they have been determined up to now, that none of the known reaction steps constitute a "power stroke" which transfers the Gibbs free energy into the vectorial ion-moving process, analogous to that a mechanical pump. To reveal the "mechanical" representation (if there is any) of the process that shifts the pumps away from their thermodynamic equilibrium to keep them going is one of the challenges to be dealt with in the field of P-type ATPases in the years to come.

Acknowledgements This work was supported financially by the Deutsche Forschungsgemeinschaft (AP 45/4) and INTAS (Project 01-0224).

\section{References}

Abramson J, Svensson-Ek M, Byrne B, Iwata S (2001) Structure of cytochrome c oxidase: a comparison of the bacterial and mitochondrial enzymes. Biochim Biophys Acta 1544:1-9

Albers RW (1967) Biochemical aspects of active transport. Ann Rev Biochem 36:727-756

Altendorf K, Siebers A, Epstein W (1992) The KDP ATPase of Escherichia coli. Ann N Y Acad Sci 671:228-243

Andersen JP (1995) Dissection of the functional domains of the sarcoplasmic reticulum $\mathrm{Ca}^{2+}$-ATPase by site-directed mutagenesis. Bioscience Reports 15:243-261

Andersen JP, Vilsen B (1988) Overview: subunit interaction and conformational states. Ca-ATPase and Na,K-ATPase compared. Prog Clin Biol Res 268A:603-622

Anner BM, Lane LK, Schwartz A, Pitts BJR (1977) A reconstituted $\mathrm{Na}^{+}+\mathrm{K}^{+}$pump in liposomes containing purified $\left(\mathrm{Na}^{+}+\mathrm{K}^{+}\right)$-ATPase from kidney medulla. Biochim Biophys Acta 467:340-345 
Anner BM, Moosmayer M (1981) Preparation of Na,K-ATPase-containing liposomes with predictable transport properties by a procedure relating the Na,K-transport capacity to the ATPase activity. J Biochem Biophys Meth 5:299-306

Apell H-J (1997) Kinetic and energetic aspects of $\mathrm{Na}^{+} / \mathrm{K}^{+}$-transport cycle steps. Ann N Y Acad Sci 834:221-230

Apell H-J, Bersch B (1987) Oxonol VI as an optical indicator for membrane potentials in lipid vesicles. Biochim Biophys Acta 903:480-494

Apell H-J, Diller A (2002) Do $\mathrm{H}^{+}$ions obscure electrogenic $\mathrm{Na}^{+}$and $\mathrm{K}^{+}$binding in the $\mathrm{E}_{1}$ state of the $\mathrm{Na}, \mathrm{K}-$ ATPase? FEBS Lett 532:198-202

Apell H-J, Karlish SJD (2001) Functional properties of Na,K-ATPase, and their structural implications, as detected with biophysical techniques. J Membr Biol 180:1-9

Apell H-J, Läuger P (1986) Quantitative analysis of pump-mediated fluxes in reconstituted lipid vesicles. Biochim Biophys Acta 861:302-310

Apell H-J, Solioz M (1990) Electrogenic transport by the Enterococcus hirae ATPase. Biochim Biophys Acta 1017:221-228

Apell H-J, Borlinghaus R, Läuger P (1987) Fast charge translocations associated with partial reactions of the Na,K-pump: II. Microscopic analysis of transient currents. J Membr Biol 97:179-191

Apell H-J, Marcus MM, Anner BM, Oetliker H, Läuger P (1985) Optical study of active ion transport in lipid vesicles containing reconstituted Na,K-ATPase. J Membr Biol 85:49-63

Apell H-J, Häring V, Roudna M (1990) Na,K-ATPase in artificial lipid vesicles. Comparison of Na,K and Na-only pumping mode. Biochim Biophys Acta 1023:81-90

Apell H-J, Roudna M, Corrie JE, Trentham DR (1996) Kinetics of the phosphorylation of Na,K-ATPase by inorganic phosphate detected by a fluorescence method. Biochemistry 35:10922-10930

Aravind L, Galperin MY, Koonin EV (1998) The catalytic domain of the P-type ATPase has the haloacid dehalogenase fold. Trends Biochem Sci 23:127-129

Artigas P, Gadsby DC (2003) The $\mathrm{Na}^{+} / \mathrm{K}^{+}$pump's intrinsic ligand-gated ion channel, unmasked by palytoxin. Proc Natl Acad Sci U S A 100:501-505

Asano S, Tabuchi Y, Takeguchi N (1989) Monoclonal antibody HK4001 completely inhibits $\mathrm{K}^{+}$-dependent ATP hydrolysis and $\mathrm{H}+$ transport of hog gastric $\mathrm{H}^{+}, \mathrm{K}^{+}$-ATPase. J Biochem (Tokyo) 106:1074-1079

Asano S, Io T, Kimura T, Sakamoto S, Takeguchi N (2001) Alanine-scanning mutagenesis of the sixth transmembrane segment of gastric $\mathrm{H}^{+}, \mathrm{K}^{+}$-ATPase $\alpha$-subunit. J. Biol. Chem. 276:31265-31273

Beauge LA, Glynn IM (1978) Commercial ATP containing traces of vanadate alters the response of $\left(\mathrm{Na}^{+}+\right.$ $\mathrm{K}^{+}$) ATPase to external potassium. Nature 272:551-552

Beaugé LA, Glynn IM (1979) Occlusion of K ions in the unphosphorylated sodium pump. Nature 280:510 512

Beguin P, Crambert G, Monnet-Tschudi F, Uldry M, Horisberger JD, Garty H, Geering K (2002) FXYD7 is a brain-specific regulator of Na,K-ATPase $\alpha$ 1- $\beta$ isozymes. EMBO J 21:3264-3273

Berrebi-Bertran I, Robert P, Camelin JC, Bril A, Souchet M (2001) The $\gamma$-subunit of $\left(\mathrm{Na}^{+}, \mathrm{K}^{+}\right)$-ATPase: a representative example of human single transmembrane protein with a key regulatory role. Cell Mol Biol 47:285-296

Bielen FV, Glitsch HG, Verdonck F (1991) Dependence of $\mathrm{Na}^{+}$pump current on external monovalent cations and membrane potential in rabbit cardiac purkinje cells. J Physiol 442:169-189

Blanco G, Koster JC, Sánchez G, Mercer RW (1995) Kinetic properties of the $\alpha 2 \beta 1$ and $\alpha 2 \beta 2$ isozymes of the Na,K-ATPase. Biochem 34:319-325

Blostein R (1979) Side-specific effects of sodium on (Na,K)-ATPase. Studies with inside-out red cell membrane vesicles. J Biol Chem 254:6673-6677

Blostein R (1983) The influence of cytoplasmic sodium concentration on the stoichiometry of the sodium pump. J Biol Chem 258:12228-12232

Boldyrev A, Lopina O, Prokopjeva V, Stubbs C, Quinn PJ (1983) The modulation of Ca-ATPase activity and protein-lipid interactions in the sarcoplasmic reticulum by ATP. Biochem Int 6:297-305

Borlinghaus R, Apell H-J, Läuger P (1987) Fast charge translocations associated with partial reactions of the Na,K-pump: I. Current and voltage transients after photochemical release of ATP. J Membr Biol 97:161-178

Bühler R, Apell H-J (1995) Sequential potassium binding at the extracellular side of the Na,K-pump. J Membr Biol 145:165-173

Bühler R, Stürmer W, Apell H-J, Läuger P (1991) Charge translocation by the Na,K-pump: I. Kinetics of local field changes studied by time-resolved fluorescence measurements. J Membr Biol 121:141-161

Butscher C, Roudna M, Apell H-J (1999) Electrogenic partial reactions of the SR-Ca-ATPase investigated by a fluorescence method. J Membr Biol 168:169-181 
Cantley LC, Josephson L, Warner R, Yanagisawa M, Lechene C, Guidotti G (1977) Vanadate is a potent $(\mathrm{Na}, \mathrm{K})-\mathrm{ATPase}$ inhibitor found in ATP derived from muscle. J Biol Chem 252:7421-7423

Capaldi RA, Aggeler R (2002) Mechanism of the $\mathrm{F}_{1} \mathrm{~F}_{0}$-type ATP synthase, a biological rotary motor. Trends Biochem Sci 27:154-160

Carafoli E (1992) The $\mathrm{Ca}^{2+}$ pump of the plasma membrane. J Biol Chem 267:2115-2118

Chiesi M, Inesi G (1980) Adenosine 5'-triphosphate dependent fluxes of manganese and hydrogen ions in sarcoplasmic reticulum vesicles. Biochem 19:2912-2918

Clarke DM, Loo TW, Inesi G, MacLennan DH (1989a) Location of high affinity $\mathrm{Ca}^{2+}$-binding sites within the predicted transmembrane domain of the sarcoplasmic reticulum $\mathrm{Ca}^{2+}$-ATPase. Nature 339:476-478

Clarke RJ, Apell H-J (1989) A stopped-flow kinetic study of the interaction of potential-sensitive oxonol dyes with lipid vesicles. Biophys Chem 34:225-237

Clarke RJ, Apell H-J, Läuger P (1989b) Pump current and $\mathrm{Na}^{+} / \mathrm{K}^{+}$coupling ratio of $\mathrm{Na}^{+} / \mathrm{K}^{+}$-ATPase in reconstituted lipid vesicles. Biochim Biophys Acta 981:326-336

Clarke RJ, Kane DJ, Apell H-J, Roudna M, Bamberg E (1998) Kinetics of $\mathrm{Na}^{+}$-dependent conformational changes of rabbit kidney $\mathrm{Na}^{+}, \mathrm{K}^{+}$-ATPase. Biophys J 75:1340-1353

Cornelius F (1989) Uncoupled $\mathrm{Na}^{+}$-efflux on reconstituted shark Na,K-ATPase is electrogenic. Biochem Biophys Res Commun 160:801-807

Cornelius F (1991) Functional reconstitution of the sodium pump. Kinetics of exchange reactions performed by reconstituted Na/K-ATPase. Biochim Biophys Acta 1071:19-66

Cornelius F, Mahmmoud YA, Christensen HR (2001) Modulation of Na,K-ATPase by associated small transmembrane regulatory proteins and by lipids. J Bioenerg Biomembr 33:415-423

Cornelius F, Møller JV (1991) Electrogenic pump current of sarcoplasmic reticulum $\mathrm{Ca}^{2+}$-ATPase reconstituted at high lipid/protein ratio. FEBS Lett 284:46-50

de Meis L (1985) Role of water in processes of energy transduction: $\mathrm{Ca}^{2+}$-transport ATPase and inorganic pyrophosphatase. Biochem Soc Symp 50:97-125

de Weer P, Gadsby DC, Rakowski RF (1988) Overview: stoichiometry and voltage dependence of the Na/ K pump. Prog Clin Biol Res 268A:421-434

de Weer P, Gadsby DC, Rakowski RF (2000) The Na/K-ATPase: a current-generating enzyme. In: Taniguchi K, Kaya S (eds) The Na/K pump and related ATPases. Elsevier Science B.V., Amsterdam, pp $27-$ 34

de Weer P, Gadsby DC, Rakowski RF (2001) Voltage dependence of the apparent affinity for external $\mathrm{Na}^{+}$ of the backward-running sodium pump. J Gen Physiol 117:315-328

Demchenko AP, Apell H-J, Stürmer W, Feddersen B (1993) Fluorescence spectroscopic studies on equilibrium dipole-relaxational dynamics of Na,K-ATPase. Biophys Chem 48:135-147

Der A, Keszthelyi L (2001) Charge motion during the photocycle of bacteriorhodopsin. Biochemistry (Mosc) 66:1234-1248

Diller A, Vagin O, Sachs G, Apell H-J (2003) Electrogenic partial reactions of the gastric H,K-ATPase. Biophys J 84:263a

Dimroth P (1987) Sodium ion transport decarboxylases and other aspects of sodium ion cycling in bacteria. Microbiol Rev 51:320-340

Dimroth P, Matthey U, Kaim G (2000) Critical evaluation of the one- versus the two-channel model for the operation of the ATP synthase's F motor. Biochim Biophys Acta 1459:506-513

Domaszewicz W, Apell H-J (1999) Binding of the third $\mathrm{Na}^{+}$ion to the cytoplasmic side of the Na,K-ATPase is electrogenic. FEBS Lett 458:241-246

Eisenrauch A, Bamberg E (1990) Voltage-dependent pump currents of the sarcoplasmic reticulum $\mathrm{Ca}^{2+}$ ATPase in planar lipid membranes. FEBS Lett 268:152-156

Eisenrauch A, Grell E, Bamberg E (1991) Voltage dependence of the Na,K-ATPase incorporated into planar lipid membranes. Soc Gen Physiol Ser 46:317-326

Epstein W, Walderhaug MO, Polarek JW, Hesse JE, Dorus E, Daniel JM (1990) The bacterial Kdp K ${ }^{+}$-ATPase and its relation to other transport ATPases, such as the $\mathrm{Na}^{+} / \mathrm{K}^{+}$- and $\mathrm{Ca}^{2+}$-ATPases in higher organisms. Philos Trans R Soc Lond B Biol Sci 326:479-486

Faller L, Jackson R, Malinowska D, Mukidjam E, Rabon E, Saccomani G, Sachs G, Smolka A (1982) Mechanistic aspects of gastric $\left(\mathrm{H}^{+}+\mathrm{K}^{+}\right)$-ATPase. Ann N Y Acad Sci 402:146-163

Faller LD, Smolka A, Sachs G (1985) The gastric H,K-ATPase. In: Martonosi AN (ed) Enzymes of biological membranes, vol 3. Plenum, New York, pp 431-448

Faller LD, Diaz RA, Scheiner-Bobis G, Farley RA (1991) Temperature dependence of the rates of conformational changes reported by fluorescein $5^{\prime}$-isothiocyanate modification of $\mathrm{H}^{+}, \mathrm{K}^{+}-$, and $\mathrm{Na}^{+}, \mathrm{K}^{+}-\mathrm{AT}$ Pases. Biochemistry 30:3503-3510

Farley RA, Faller LD (1985) The amino acid sequence of an active site peptide from the H,K-ATPase of gastric mucosa. J Biol Chem 260:3899-3901 
Fedosova NU, Cornelius F, Klodos I (1995) Fluorescent styryl dyes as probes for Na,K-ATPase reaction mechanism: significance of the charge of the hydrophilic moiety of RH dyes. Biochemistry 34:1680616814

Fendler K, Grell E, Haubs M, Bamberg E (1985) Pump currents generated by the purified $\mathrm{Na}^{+} \mathrm{K}^{+}$-ATPase from kidney on black lipid membranes. EMBO J 4:3079-3085

Fendler K, van der Hijden H, Nagel G, de Pont JJ, Bamberg E (1988) Pump currents generated by renal $\mathrm{Na}^{+} \mathrm{K}^{+}$-ATPase and gastric $\mathrm{H}^{+} \mathrm{K}^{+}$-ATPase on black lipid membranes. Prog Clin Biol Res 268A:501510

Fendler K, Jaruschewski S, Hobbs A, Albers W, Froehlich JP (1993) Presteady-state charge translocation in NaK-ATPase from Eel electric organ. J Gen Physiol 102:631-666

Ferreira ST, Coelho-Sampaio T (1996) Intrinsic fluorescence as a probe of structure-function relationships in $\mathrm{Ca}^{2+}$-transport ATPases. Bioscience Reports 16:87-106

Fluhler E, Burnham VG, Loew LM (1985) Spectra, membrane binding, and potentiometric responses of new charge shift probes. Biochemistry 24:5749-5755

Forbush B III (1984a) An apparatus for rapid kinetic analysis of isotopic efflux from membrane vesicles and of ligand dissociation from membrane proteins. Anal Biochem 140:495-505

Forbush B III (1984b) $\mathrm{Na}^{+}$movement in a single turnover of the $\mathrm{Na}$ pump. Proc Natl Acad Sci USA 81:5310-5314

Forbush B III (1987) Rapid release of ${ }^{42} \mathrm{~K}$ and ${ }^{86} \mathrm{Rb}$ from an occluded state of the Na,K-pump in the presence of ATP or ADP. J Biol Chem 262:11104-11115

Forgac M (1999) Structure and properties of the clathrin-coated vesicle and yeast vacuolar V-ATPases. J Bioenerg Biomembr 31:57-65

Froehlich JP, Heller PF (1985) Transient-state kinetics of the ADP-insensitive phosphoenzyme in sarcoplasmic reticulum: implications for transient-state calcium translocation. Biochemistry 24:126-136

Gaballo A, Zanotti F, Papa S (2002) Structures and interactions of proteins involved in the coupling function of the protonmotive $\mathrm{F}_{\mathrm{o}} \mathrm{F}_{1}$-ATP synthase. Curr Protein Pept Sci 3:451-460

Gadsby DC (1984) The Na/K pump of cardiac cells. Ann Rev Biophys Bioeng 13:373-398

Gadsby DC, Kimura J, Noma A (1985) Voltage dependence of $\mathrm{Na} / \mathrm{K}$ pump current in isolated heart cells. Nature 315:63-65

Gadsby DC, Rakowski RF, de Weer P (1993) Extracellular access to the Na,K pump: pathway similar to ion channel. Science 260:100-103

Garty H, Lindzen M, Scanzano R, Aizman R, Fuzesi M, Goldshleger R, Farman N, Blostein R, Karlish SJ (2002) A functional interaction between CHIF and Na-K-ATPase: implication for regulation by FXYD proteins. Am J Physiol Renal Physiol 283:F607-F615

Gatto C, McLoud SM, Kaplan JH (2001) Heterologous expression of $\mathrm{Na}^{+}-\mathrm{K}^{+}$-ATPase in insect cells: intracellular distribution of pump subunits. Am J Physiol Cell Physiol 281:C982-C992

Geering K (2001) The functional role of $\beta$ subunits in oligomeric P-type ATPases. J Bioenerg Biomembr 33:425-438

Geering K, Crambert G, Yu C, Korneenko TV, Pestov NB, Modyanov NN (2000) Intersubunit interactions in human X,K-ATPases: role of membrane domains M9 and M10 in the assembly process and association efficiency of human, nongastric H,K-ATPase $\alpha$ subunits (ATP1al1) with known $\beta$ subunits. Biochemistry 39:12688-12698

Gerencser GA (1996) The chloride pump: a Cl--translocating P-type ATPase. Crit Rev Biochem Mol Biol 31:303-337

Glitsch HG (2001) Electrophysiology of the sodium-potassium-ATPase in cardiac cells. Physiol Rev 81:1791-1826

Glitsch HG, Tappe A (1995) Change of $\mathrm{Na}^{+}$pump current reversal potential in sheep cardiac Purkinje cells with varying free energy of ATP hydrolysis. J Physiol 484:605-616

Glynn IM (1985) The $\mathrm{Na}^{+}, \mathrm{K}^{+}$-transporting adenosine triphosphatase. In: Martonosi AN (ed) Membrane transport. Plenum Press, New York, pp 35-114

Glynn IM, Richards DE (1982) Occlusion of rubidium ions by the sodium-potassium pump: its implications for the mechanism of potassium transport. J Physiol 330:17-43

Goldshlegger R, Karlish SJ, Rephaeli A, Stein WD (1987) The effect of membrane potential on the mammalian sodium-potassium pump reconstituted into phospholipid vesicles. J Physiol (Lond) 387:331355

Goldshleger R, Shahak Y, Karlish SJD (1990) Electrogenic and electroneutral transport modes of renal Na/ K ATPase reconstituted into proteoliposomes. J Membr Biol 113:139-154

Goldshleger R, Patchornik G, Shimon MB, Tal DM, Post RL, Karlish SJ (2001) Structural organization and energy transduction mechanism of $\mathrm{Na}^{+}, \mathrm{K}^{+}$-ATPase studied with transition metal-catalyzed oxidative cleavage. J Bioenerg Biomembr 33:387-399 
Green NM, MacLennan DH (2002) Calcium callisthenics. Nature 418:598-599

Guennoun S, Horisberger JD (2000) Structure of the 5th transmembrane segment of the Na,K-ATPase $\alpha$ subunit: a cysteine-scanning mutagenesis study. FEBS Lett 482:144-148

Guennoun S, Horisberger JD (2002) Cysteine-scanning mutagenesis study of the sixth transmembrane segment of the Na,K-ATPase $\alpha$ subunit. FEBS Lett 513:277-281

Hartung K, Grell E, Hasselbach W, Bamberg E (1987) Electrical pump currents generated by the Ca ${ }^{2+}$-ATPase of sarcoplasmic reticulum vesicles adsorbed on black lipid membranes. Biochim Biophys Acta 900:209-220

Hartung K, Froehlich JP, Fendler K (1997) Time-resolved charge translocation by the Ca-ATPase from sarcoplasmic reticulum after an ATP concentration jump. Biophys J 72:2503-2514

Haupts U, Tittor J, Oesterhelt D (1999) Closing in on bacteriorhodopsin: progress in understanding the molecule. Annu Rev Biophys Biomol Struct 28:367-399

Hebert H, Xian R, Thomsen K, Maunsbach AB (2000) Structure of renal Na,K-ATPase as observed by cryo-EM of 2-D crystals. In: Taniguchi K, Kaya S (eds) Na/K-ATPase and related ATPases. Elsevier, Amsterdam, pp 43-48

Hegyvary C, Post RL (1971) Binding of adenosine triphosphate to sodium and potassium ion-stimulated adenosine triphosphatase. J Biol Chem 246:5234-5240

Helmich-de Jong ML, van Emst-de Vries SE, de Pont JJ (1987) Conformational states of $\left(\mathrm{K}^{+}+\mathrm{H}^{+}\right)$-ATPase studied using tryptic digestion as a tool. Biochim Biophys Acta 905:358-370

Hermsen HP, Koenderink JB, Swarts HG, de Pont JJ (2000) The carbonyl group of glutamic acid-795 is essential for gastric $\mathrm{H}^{+}, \mathrm{K}^{+}$- ATPase activity. Biochemistry 39:1330-1337

Hermsen HP, Swarts HG, Wassink L, Koenderink JB, Willems PH, de Pont JJ (2001) Mimicking of $\mathrm{K}^{+}$ activation by double mutation of glutamate 795 and glutamate 820 of gastric $\mathrm{H}^{+}, \mathrm{K}^{+}$-ATPase. Biochemistry 40:6527-6533

Heyse S, Wuddel I, Apell H-J, Stürmer W (1994) Partial reactions of the Na,K-ATPase: determination of rate constants. J Gen Physiol 104:197-240

Hilgemann DW (1994) Channel-like function of the Na,K pump probed at microsecond resolution in giant membrane patches. Science 263:1429-1432

Hill, T. L. (1977) Free energy transduction in biology. Academic Press, New York

Hill, T. L. (1989) Free energy transduction and biochemical cycle kinetics. Springer, New York

Holmgren M, Rakowski RF (1994) Presteady-state transient currents mediated by the Na/K pump in internally perfused Xenopus oocytes. Biophys J 66:912-922

Holmgren M, Wagg J, Bezanilla F, Rakowski RF, de Weer P, Gadsby DC (2000) Three distinct and sequential steps in the release of sodium ions by the $\mathrm{Na}^{+} / \mathrm{K}^{+}$-ATPase. Nature 403:898-901

Horisberger J-D, Giebisch G (1989) Na-K pump current in the Amphiuma collecting tubule. J Gen Physiol 94:493-510

Horisberger J-D, Jaunin P, Good PJ, Rossier BC, Geering K (1991) Coexpression of $\alpha_{1}$ with putative $\beta_{3}$ subunits results in functional $\mathrm{Na}^{+} / \mathrm{K}^{+}$pumps in Xenopus oocytes. Proc Natl Acad Sci USA 88:83978400

Humphrey PA, Lupfert C, Apell HJ, Cornelius F, Clarke RJ (2002) Mechanism of the rate-determining step of the $\mathrm{Na}^{+}, \mathrm{K}^{+}$-ATPase pump cycle. Biochemistry 41:9496-9507

Inesi G (1987) Sequential mechanism of calcium binding and translocation in sarcoplasmic reticulum adenosine triphosphatase. J Biol Chem 262:16338-16342

Inesi G, de Meis L (1989) Regulation of steady state filling in sarcoplasmic reticulum. Roles of back-inhibition, leakage, and slippage of the calcium pump. J Biol Chem 264:5929-5936

Inesi G, Sagara Y (1992) Thapsigargin, a high affinity and global inhibitor of intracellular $\mathrm{Ca}^{2+}$ transport ATPases. Arch Biochem Biophys 298:313-317

Inesi G, Cantilina T, Yu X, Nikic D, Sagara Y, Kirtley ME (1992) Long-range intramolecular linked functions in activation and inhibition of SERCA ATPases. Ann N Y Acad Sci 671:32-47

Jaunin P, Jaisser F, Beggah AT, Takeyasu K, Mangeat P, Rossier BC, Horisberger JD, Geering K (1993) Role of the transmembrane and extracytoplasmic domain of $\beta$ subunits in subunit assembly, intracellular transport, and functional expression of Na,K-pumps. J Cell Biol 123:1751-1759

Jørgensen PL (1974) Isolation of $\left(\mathrm{Na}^{+}+\mathrm{K}^{+}\right)$-ATPase. Meth Enzymol 32:277-290

Jørgensen PL, Pedersen PA (2001) Structure-function relationships of $\mathrm{Na}^{+}, \mathrm{K}^{+}$, ATP, or $\mathrm{Mg}^{2+}$ binding and energy transduction in Na,K-ATPase. Biochim Biophys Acta 1505:57-74

Jørgensen PL, Jorgensen JR, Pedersen PA (2001) Role of conserved TGDGVND-loop in $\mathrm{Mg}^{2+}$ binding, phosphorylation, and energy transfer in Na,K-ATPase. J Bioenerg Biomembr 33:367-377

Kapakos JG, Steinberg M (1982) Fluorescent labeling of $\left(\mathrm{Na}^{+}+\mathrm{K}^{+}\right)$-ATPase by 5-iodoacetamidofluorescein. Biochim Biophys Acta 693:493-496 
Kapakos JG, Steinberg M (1986) Ligand binding to (Na,K)-ATPase labeled with 5-iodoacetamidofluorescein. J Biol Chem 261:2064-2069

Karlish SJ (1988) Use of formycin nucleotides, intrinsic protein fluorescence, and fluorescein isothiocyanate-labeled enzymes for measurement of conformational states of $\mathrm{Na}+\mathrm{K}+-\mathrm{ATPase}$. Methods Enzymol 156:271-277

Karlish SJ, Glynn IM (1974) An uncoupled efflux of sodium ions from human red cells, probably associated with Na-dependent ATPase activity. Ann N Y Acad Sci 242:461-470

Karlish SJ, Pick U (1981) Sidedness of the effects of sodium and potassium ions on the conformational state of the sodium-potassium pump. J Physiol 312:505-529

Karlish SJ, Yates DW, Glynn IM (1978) Conformational transitions between $\mathrm{Na}^{+}$-bound and $\mathrm{K}^{+}$-bound forms of $\left(\mathrm{Na}^{+}+\mathrm{K}^{+}\right)$-ATPase, studied with formycin nucleotides. Biochim Biophys Acta 525:252-264

Karlish SJ, Lieb WR, Stein WD (1982) Combined effects of ATP and phosphate on rubidium exchange mediated by Na-K-ATPase reconstituted into phospholipid vesicles. J Physiol 328:333-350

Karlish, SJD, Yates DW (1978) Tryptophan fluorescence of $\left(\mathrm{Na}^{+}+\mathrm{K}^{+}\right)$-ATPase as a tool for study of the enzyme mechanism. Biochim Biophys Acta 527:115-130

Keeling DJ, Laing SM, Senn-Bilfinger J (1988) SCH 28080 is a lumenally acting, $\mathrm{K}^{+}$-site inhibitor of the gastric $\left(\mathrm{H}^{+}+\mathrm{K}^{+}\right)$-ATPase. Biochem Pharmacol 37:2231-2236

Kirley TL, Wang T, Wallick ET, Lane LK (1985) Homology of ATP binding sites from $\mathrm{Ca}^{2+}$ and (Na,K)ATPases: comparison of the amino acid sequences of fluorescein isothiocyanate labeled peptides. Biochem Biophys Res Commun 130:732-738

Klaassen CH, Van Uem TJ, De Moel MP, De Caluwe GL, Swarts HG, de Pont JJ (1993) Functional expression of gastric H,K-ATPase using the baculovirus expression system. FEBS Lett 329:277-282

Klodos I, Forbush B, III (1988) Rapid conformational changes of the Na/K pump revealed by a fluorescent dye RH-160. J Gen Physiol 92:46a

Kühlbrandt W, Auer M, Scarborough GA (1998) Structure of the P-type ATPases. Curr Opin Struct Biol 8:510-516

Lafaire AV, Schwarz W (1985) Voltage-dependent, ouabain-sensitive current in the membrane of oocytes of xenopus laevis. In: Glynn IM, Ellory JC (eds) The sodium pump. The Company of Biologists, Ltd., London,pp 223-225

Lancaster CR (2002) A P-type ion pump at work. Nat Struct Biol 9:643-645

Lanyi JK, Luecke H (2001) Bacteriorhodopsin. Curr Opin Struct Biol 11:415-419

Läuger P (1979) A channel mechanism for electrogenic ion pumps. Biochim Biophys Acta 552:143-161

Läuger P (1984) Thermodynamic and kinetic properties of electrogenic ion pumps. Biochim Biophys Acta 779:307-341

Läuger, P. (1991) Electrogenic ion pumps. Sinauer Assoc., Sunderland, MA

Läuger P, Apell H-J (1986) A microscopic model for the current-voltage behavior of the Na,K-pump. Eur Biophys J 13:309-321

Läuger P, Apell H-J (1988) Voltage dependence of partial reactions of the $\mathrm{Na}^{+} / \mathrm{K}^{+}$pump: predictions from microscopic models. Biochim Biophys Acta 945:1-10

Lederer WJ, Nelson MT (1984) Sodium pump stoichiometry determined by simultaneous measurements of sodium efflux and membrane current in barnacle. J Physiol 348:665-677

Lee AG, East JM (2001) What the structure of a calcium pump tells us about its mechanism. Biochem J 356:665-683

Lin SH, Smirnova IN, Kasho VN, Faller LD (1997) Eosin, energy transfer, and RH421 report the same conformational change in sodium pump as fluorescein. Ann N Y Acad Sci 834:442-444

Linnertz H, Kost H, Obsil T, Kotyk A, Amler E, Schoner W (1998a) Erythrosin 5'-isothiocyanate labels Cys549 as part of the low-affinity ATP binding site of $\mathrm{Na}^{+} / \mathrm{K}^{+}$-ATPase. FEBS Lett 441:103-105

Linnertz H, Urbanova P, Obsil T, Herman P, Amler E, Schoner W (1998b) Molecular distance measurements reveal an $(\alpha \beta)_{2}$ dimeric structure of $\mathrm{Na}^{+} / \mathrm{K}^{+}$-ATPase. J Biol Chem 273:28813-28821

Loew LM, Scully S, Simpson L, Waggoner AS (1979) Evidence for a charge-shift electrochromic mechanism in a probe of membrane potential. Nature 281:497-499

Lytton J, Westlin M, Hanley MR (1991) Thapsigargin inhibits the sarcoplasmic or endoplasmic reticulum Ca-ATPase family of calcium pumps. J Biol Chem 266:17067-17071

MacLennan DH, Brandl CJ, Korczak B, Green NM (1985) Amino-acid sequence of a $\mathrm{Ca}^{2+}+\mathrm{Mg}^{2+}$-dependent ATPase from rabbit muscle sarcoplasmic reticulum, deduced from its complementary DNA sequence. Nature 316:696-700

MacLennan DH, Rice WJ, Green NM (1997) The mechanism of $\mathrm{Ca}^{2+}$ transport by sarco(endo)plasmic reticulum $\mathrm{Ca}^{2+}$-ATPases. J Biol Chem 272:28815-28818

Madeira VM (1978) Proton gradient formation during transport of Ca2+ by sarcoplasmic reticulum. Arch Biochem Biophys 185:316-325 
McDonough AA, Geering K, Farley RA (1990) The sodium pump needs its $\beta$ subunit. FASEB J. 4:15981605

Mense M, Dunbar LA, Blostein R, Caplan MJ (2000) Residues of the fourth transmembrane segments of the Na,K-ATPase and the gastric H,K-ATPase contribute to cation selectivity. J. Biol. Chem. 275:1749-1756

Mense M, Rajendran V, Blostein R, Caplan MJ (2002) Extracellular domains, transmembrane segments, and intracellular domains interact to determine the cation selectivity of $\mathrm{Na}, \mathrm{K}$ - and gastric $\mathrm{H}, \mathrm{K}-\mathrm{ATPase}$. Biochemistry 41:9803-9812

Meyer RA, Kuchmerick MJ, Brown TR (1982) Application of ${ }^{31} \mathrm{P}-\mathrm{NMR}$ spectroscopy to the study of striated muscle metabolism. Am J Physiol 242:C1-11

Michel H (1999) Cytochrome c oxidase: catalytic cycle and mechanisms of proton pumping-a discussion. Biochemistry 38:15129-15140

Mitchell P, Moyle J (1974) The mechanism of proton translocation in reversible proton-translocating adenosine triphosphatases. Biochem Soc Spec Publ 4:91-111

Møller JV, Juul B, le Maire M (1996) Structural organization, ion transport, and energy transduction of Ptype ATPases. Biochim Biophys Acta 1286:1-51

Moore JW, Pearson RG (1981) Kinetics and mechanism, 3rd ed. Wiley, New York

Nagel G, Bashi E, Slayman CL (1991) Spectral tagging of reaction substates in a sodium pump analogue: The plasma membrane $\mathrm{H}^{+}$-ATPase of Neurospora. In: Kaplan JH, de Weer P (eds) The sodium pump: recent developments. The Rockefeller University Press, New York, pp 493-498

Nakao M, Gadsby DC (1986) Voltage dependence of Na translocation by the Na/K pump. Nature 323:628 630

Nelson, N. (1995) Organellar proton-ATPases. Springer Verlag, New York

Nishie I, Anzai K, Yamamoto T, Kirino Y (1990) Measurement of steady-state $\mathrm{Ca}^{2+}$ pump current caused by purified $\mathrm{Ca}^{2+}$-ATPase of sarcoplasmic reticulum incorporated into a planar bilayer lipid membrane. J Biol Chem 265:2488-2491

Orlowski S, Champeil P (1991) The two calcium ions initially bound to nonphosphorylated sarcoplasmic reticulum $\mathrm{Ca}^{2+}$-ATPase can no longer be kinetically distinguished when they dissociate from phosphorylated ATPase toward the lumen. Biochemistry 30:11331-11342

Papa S, Zanotti F, Gaballo A (2000) The structural and functional connection between the catalytic and proton translocating sectors of the mitochondrial F1F0-ATP synthase. J Bioenerg Biomembr 32:401-411

Pavlov KV, Sokolov VS (2000) Electrogenic ion transport by $\mathrm{Na}^{+}, \mathrm{K}^{+}$-ATPase. Membr Cell Biol 13:745788

Pedersen M, Roudna M, Beutner S, Birmes M, Reifers B, Martin H-D, Apell H-J (2001) Detection of charge movements in ion pumps by a family of styryl dyes. J Membr Biol 185:221-236

Pedersen PA, Rasmussen JH, Jørgensen PL (1996) Expression in high yield of pig $\alpha 1 \beta 1 \mathrm{Na}, \mathrm{K}-\mathrm{ATPase}$ and inactive mutants D369 N and D807 N in Saccharomyces cerevisiae. J Biol Chem 271:214-222

Peinelt C, Apell H-J (2002) Kinetics of the $\mathrm{Ca}^{2+}, \mathrm{H}^{+}$and $\mathrm{Mg}^{2+}$ interaction with the ion-binding sites of the SR-Ca-ATPase. Biophys J 82:170-181

Peinelt C, Apell H-J (2003) Time-resolved partial reactions of the SR Ca-ATPase investigated with a fluorescent styryl dye. Ann N Y Acad Sci (in press)

Peluffo RD, Berlin JR (1997) Electrogenic $\mathrm{K}^{+}$transport by the $\mathrm{Na}^{+}-\mathrm{K}^{+}$pump in rat cardiac ventricular myocytes. J Physiol 501:33-40

Pintschovius J, Fendler K (1999) Charge translocation by the $\mathrm{Na}^{+} / \mathrm{K}^{+}$-ATPase investigated on solid supported membranes: rapid solution exchange with a new technique. Biophys J 76:814-826

Post RL, Hegyvary C, Kume S (1972) Activation by adenosine triphosphate in the phosphorylation kinetics of sodium and potassium ion transport adenosine triphosphatase. J Biol Chem 247:6530-6540

Pratap PR, Robinson JD (1993) Rapid kinetic analyses of the $\mathrm{Na}^{+} / \mathrm{K}^{+}$-ATPase distinguish among different criteria for conformational change. Biochim Biophys Acta 1151:89-98

Rakowski RF (1989) Simultaneous measurement of changes in current and tracer flux in voltage-clamped squid giant axon. Biophys J 55:663-671

Rakowski RF, Gadsby DC, de Weer P (1987) Voltage-clamp reversal of the sodium pump in dialyzed squid giant axons. Biol Bull 173:445-446

Rakowski RF, Vasilets LA, LaTona J, Schwarz W (1990) A negative slope in the current-voltage relationship of the $\mathrm{Na}^{+} / \mathrm{K}^{+}$pump in Xenopus Oocytes produced by reduction of external $\left[\mathrm{K}^{+}\right]$. J Membr Biol 121:171-187

Reinhardt R, Lindemann B, Anner BM (1984) Leakage-channel conductance of single $\left(\mathrm{Na}^{+}+\mathrm{K}^{+}\right)$-ATPase molecules incorporated into planar bilayers by fusion of liposomes. Biochim Biophys Acta 774:147150 
Rephaeli A, Richards DE, Karlish SJ (1986) Electrical potential accelerates the E1P(Na)-E2P conformational transition of (Na,K)-ATPase in reconstituted vesicles. J Biol Chem 261:12437-12440

Rulli SJ, Louneva NM, Skripnikova EV, Rabon EC (2001) Site-directed mutagenesis of cation coordinating residues in the gastric H,K-ATPase. Arch Biochem Biophys 387:27-34

Sachs G, Besancon M, Shin JM, Mercier F, Munson K, Hersey S (1992) Structural aspects of the gastric H,K-ATPase. J Bioenerg Biomembr 24:301-308

Sachs JR (1977) Kinetic evaluation of the Na-K pump reaction mechanism. J Physiol 273:489-514

Saraste M, Sibbald PR, Wittinghofer A (1990) The P-loop-a common motif in ATP- and GTP-binding proteins. Trends Biochem Sci 15:430-434

Scarborough GA (1999) Structure and function of the P-type ATPases. Curr Opin Cell Biol 11:517-522

Schatzmann HJ (1953) Herzglykoside als Hemmstoffe für den aktiven Kalium und Natrium Transport durch die Erytrocytenmembran. Helv Physiol Pharmacol Acta 11:346-354

Schatzmann HJ (1989) The calcium pump of the surface membrane and of the sarcoplasmic reticulum. Annu Rev Physiol 51:473-485

Scheiner-Bobis G, Farley RA (1994) Subunit requirements for expression of functional sodium pumps in yeast cells. Biochim Biophys Acta 1193:226-234

Schneeberger A, Apell H-J (1999) Ion selectivity of the cytoplasmic binding sites of the Na,K-ATPase: I. Sodium binding is associated with a conformational rearrangement. J Membr Biol 168:221-228

Schneeberger A, Apell H-J (2001) Ion selectivity of the cytoplasmic binding sites of the Na,K-ATPase: II. Competition of various cations. J Membr Biol 179:263-273

Schwarz W Gu Q (1988) Characteristics of the $\mathrm{Na}^{+} / \mathrm{K}^{+}$-ATPase from Torpedo californica expressed in Xenopus oocytes: a combination of tracer flux measurements with electrophysiological measurements. Biochim Biophys Acta 945:167-174

Seidler NW, Jona I, Vegh M, Martonosi A (1989) Cyclopiazonic acid is a specific inhibitor of the Ca2+ATPase of sarcoplasmic reticulum. J Biol Chem 264:17816-17823

Seifert K, Fendler K, Bamberg E (1993) Charge transport by ion translocating membrane proteins on solid supported membranes. Biophys J 64:384-391

Sen AK, Post RL (1964) Stoichiometry and localization of adenosine triphosphate-dependent sodium and potassium transport in the erythrocyte. J Biol Chem 239:345-352

Sen PC, Kapakos JG, Steinberg M (1981) Modification of $\left(\mathrm{Na}^{+}+\mathrm{K}^{+}\right)$-dependent ATPase by fluorescein isothiocyanate: evidence for the involvement of different amino groups at different $\mathrm{pH}$ values. Arch Biochem Biophys 211:652-661

Senior AE, Nadanaciva S, Weber J (2002) The molecular mechanism of ATP synthesis by F1F0-ATP synthase. Biochim Biophys Acta 1553:188-211

Shin JM, Goldshleger R, Munson KB, Sachs G, Karlish SJ (2001) Selective $\mathrm{Fe}^{2+}$-catalyzed oxidative cleavage of gastric $\mathrm{H}^{+}, \mathrm{K}^{+}$-ATPase: implications for the energy transduction mechanism of P-type cation pumps. J Biol Chem 276:48440-48450

Shull GE, Greeb J (1988) Molecular cloning of two isoforms of the plasma membrane $\mathrm{Ca}^{2+}$-transporting ATPase from rat brain. J Biol Chem 263:8646-8657

Shull GE, Lingrel JB (1986) Molecular cloning of the rat stomach $\left(\mathrm{H}^{+}+\mathrm{K}^{+}\right)$-ATPase. J Biol Chem 261:16788-16791

Shull GE, Schwartz A, Lingrel JB (1985) Amino-acid sequence of the catalytic subunit of the $\left(\mathrm{Na}^{+}+\mathrm{K}^{+}\right) \mathrm{AT}-$ Pase deduced from a complementary DNA. Nature 316:691-695

Simons TJB (1974) Potassium: potassium exchange catalysed by the sodium pump in human red cells. J Physiol 237:123-155

Skou JC, Esmann M (1981) Eosin, a fluorescent probe of ATP binding to the $\left(\mathrm{Na}^{+}+\mathrm{K}^{+}\right)$-ATPase. Biochim Biophys Acta 647:232-240

Skou JC, Esmann M (1983) The effects of $\mathrm{Na}^{+}$and $\mathrm{K}^{+}$on the conformational transitions of $\left(\mathrm{Na}^{+}+\mathrm{K}^{+}\right)$ATPase. Biochim Biophys Acta 746:101-113

Slayman CL, Sanders D (1985) Steady-state kinetic analysis of an electroenzyme. Biochem Soc Symp 50:11-29

Sokolov VS, Apell H-J, Corrie JE, Trentham DR (1998) Fast transient currents in Na,K-ATPase induced by ATP concentration jumps from the P3-[1-(3',5'-dimethoxyphenyl)-2-phenyl-2-oxo]ethyl ester of ATP. Biophys J 74:2285-2298

Stankiewicz PJ, Tracey AS, Crans DC (1995) Inhibition of phosphate-metabolizing enzymes by oxovanadium(V) complexes. Met Ions Biol Syst 31:287-324

Stein WD (1990) Energetics and the design principles of the Na/K-ATPase. J Theor Biol 147:145-159

Steinberg M, Karlish SJD (1989) Studies on conformational changes in Na,K-ATPase labeled with 5iodoacetamidofluorescein. J Biol Chem 264:2726-2734 
Stengelin M, Fendler K, Bamberg E (1993) Kinetics of transient pump currents generated by the $(\mathrm{H}, \mathrm{K})$ ATPase after an ATP concentration jump. J Membr Biol 132:211-227

Stoeckenius W (1999) Bacterial rhodopsins: evolution of a mechanistic model for the ion pumps. Protein Sci 8:447-459

Stürmer W, Apell H-J, Wuddel I, Läuger P (1989) Conformational transitions and change translocation by the Na,K pump: comparison of optical and electrical transients elicited by ATP-concentration jumps J Membr Biol 110:67-86

Stürmer W, Bühler R, Apell H-J, Läuger P (1991) Charge translocation by the Na,K-pump: II. Ion binding and release at the extracellular face. J Membr Biol 121:163-176

Sweadner KJ, Donnet C (2001) Structural similarities of Na,K-ATPase and SERCA, the Ca ${ }^{2+}$-ATPase of the sarcoplasmic reticulum. Biochem J 356:685-704

Sze H, Ward JM, Lai S (1992) Vacuolar $\mathrm{H}^{+}$-translocating ATPases from plants: structure, function, and isoforms. J Bioenerg Biomembr 24:371-381

Tal DM, Capasso JM, Munson K, Karlish SJ (2001) Proximity of transmembrane segments M3 and M1 of the $\alpha$ subunit of $\mathrm{Na}^{+}, \mathrm{K}^{+}$-ATPase revealed by specific oxidative cleavage mediated by a complex of $\mathrm{Cu}^{2+}$ ions and 4,7-diphenyl-1,10-phenanthroline. Biochemistry 40:12505-12514

Therien AG Pu HX, Karlish SJ, Blostein R (2001) Molecular and functional studies of the $\gamma$ subunit of the sodium pump. J Bioenerg Biomembr 33:407-414

Toyoshima C, Nomura H (2002) Structural changes in the calcium pump accompanying the dissociation of calcium. Nature 418:605-611

Toyoshima C, Nakasako M, Nomura H, Ogawa H (2000) Crystal structure of the calcium pump of sarcoplasmatic reticulum at $2.6 \AA$ resolution. Nature 405:647-655

Tyson PA, Steinberg M, Wallick ET, Kirley TL (1989) Identification of the 5-iodoacetamidofluorescein reporter site on the Na,K-ATPase. J Biol Chem 264:726-734

Vagin O, Denevich S, Munson K, Sachs G (2002) SCH28080, a $\mathrm{K}^{+}$-competitive inhibitor of the gastric $\mathrm{H}, \mathrm{K}-\mathrm{ATPase}$, binds near the M5-6 luminal loop, preventing $\mathrm{K}^{+}$access to the ion binding domain. Biochemistry 41:12755-12762

van der Hijden HT, Grell E, de Pont JJ, Bamberg E (1990) Demonstration of the electrogenicity of proton translocation during the phosphorylation step in gastric $\mathrm{H}^{+} \mathrm{K}^{+}$-ATPase. J Membr Biol 114:245-256

Vasilets LA, Omay HS, Ohta T, Noguchi S, Kawamura M, Schwarz W (1991) Stimulation of the $\mathrm{Na}^{+} / \mathrm{K}^{+}$ pump by external $\left[\mathrm{K}^{+}\right]$is regulated by voltage-dependent gating. J Biol Chem 266:16285-16288

Vilsen B (1995) Structure-function relationships in the $\mathrm{Ca}^{2+}$-ATPase of sarcoplasmic reticulum studied by use of the substrate analogue CrATP and site-directed mutagenesis. Comparison with the $\mathrm{Na}^{+}, \mathrm{K}^{+}-\mathrm{AT}$ Pase. Acta Physiol Scand Suppl 624:1-146

Visser NV, van Hoek A, Visser AJ, Frank J, Apell H-J, Clarke RJ (1995) Time-resolved fluorescence investigations of the interaction of the voltage-sensitive probe RH421 with lipid membranes and proteins. Biochemistry 34:11777-11784

Walz D, Caplan SR (1988) Energy coupling and thermokinetic balancing in enzyme kinetics. Microscopic reversibility and detailed balance revisited. Cell Biophys 12:13-28

Wikstrom M (2000) Mechanism of proton translocation by cytochrome c oxidase: a new four-stroke histidine cycle. Biochim Biophys Acta 1458:188-198

Wuddel I, Apell H-J (1995) Electrogenicity of the sodium transport pathway in the Na,K-ATPase probed by charge-pulse experiments. Biophys J 69:909-921

Yu X, Carroll S, Rigaud J-L, Inesi G (1993) $\mathrm{H}^{+}$countertransport and electrogenicity of the sarcoplasmic reticulum $\mathrm{Ca}^{2+}$ pump in reconstituted proteoliposomes. Biophys J 64:1232-1342

Yu X, Hao L, Inesi G (1994) A pK change of Acidic residues contributes to cation countertransport in the Ca-ATPase of sarcoplasmic reticulum. J Biol Chem 269:16656-16661

Zhang P, Toyoshima C, Yonekura K, Green NM, Stokes DL (1998) Structure of the calcium pump from sarcoplasmic reticulum at 8-A resolution. Nature 392:835-839

Zhao J, Vasilets LA, Gu Q, Ishii T, Takeyas K, Schwarz W (1997) Transport activity of a chimeric $\mathrm{Na}^{+}, \mathrm{K}^{+}-$ ATPase with $\mathrm{Ca}^{2+} /$ calmodulin binding domain from $\mathrm{Ca}^{2+}$-ATPase in Xenopus oocytes. Ann N Y Acad Sci 834:372-375 